University of Tennessee Health Science Center

UTHSC Digital Commons

$12-2008$

\title{
Regulation of the Human Parainfluenza Virus (hPIV3) Fusion Protein
}

Amanda Ruth Chapman

University of Tennessee Health Science Center

Follow this and additional works at: https://dc.uthsc.edu/dissertations

Part of the Amino Acids, Peptides, and Proteins Commons, Medical Cell Biology Commons, and the Virus Diseases Commons

\section{Recommended Citation}

Chapman, Amanda Ruth, "Regulation of the Human Parainfluenza Virus (hPIV3) Fusion Protein" (2008). Theses and Dissertations (ETD). Paper 339. http://dx.doi.org/10.21007/etd.cghs.2008.0047.

This Thesis is brought to you for free and open access by the College of Graduate Health Sciences at UTHSC Digital Commons. It has been accepted for inclusion in Theses and Dissertations (ETD) by an authorized administrator of UTHSC Digital Commons. For more information, please contact jwelch30@uthsc.edu. 


\title{
Regulation of the Human Parainfluenza Virus (hPIV3) Fusion Protein
}

\begin{abstract}
Paramyxoviruses include a number of important human pathogens, including measles virus, mumps virus, and the human parainfluenza viruses (hPIV) 1-4, as well as several animal pathogens, such as Sendai virus, Nipah virus and Hendra virus. The creation of effective drugs and vaccines against this family of viruses would play an important role in decreasing the prevalence of these viruses and contributing to the health of both humans and animals worldwide. The purpose of this work was to determine how the fusion (F) protein is regulated with a focus on the heptad repeat $B$ (HRB) region of the $\mathrm{F}$ protein located in the ectodomain, directly adjacent to the transmembrane domain. This region has been suggested to play important roles in the initiation of fusion
\end{abstract}

(Gravel 2003) as well as in the formation of the final hairpin structure that drives fusion (Russell 2001). My investigation of the HRB region of the parainfluenza fusion ( $F$ ) protein has been to characterize the structure of this domain in the pre-fusion form of the $\mathrm{F}$ protein in order to better understand the role it plays in fusion. An understanding of how $\mathrm{F}$ protein conformational changes are regulated may lead to the creation of more effective therapies against paramyxoviruses in general. A crystal structure obtained from the pre-fusion PIV5 F protein (Yin 2006) reveals that the HRB domain is in a triple stranded coiled coil conformation. However, in order to obtain the structure, a trimerization domain was used for structure stabilization. It is not known if the trimerization domain influenced the resulting crystal structure. My research has investigated the structure of the HRB region by creating mutations in both the pre-fusion hPIV3 F protein and peptides derived from the HRB region. Although much work still remains, preliminary results are consistent with the HRB region of the hPIV3 F protein forming a triple stranded coiled coil in the pre-fusion conformation.

\section{Document Type}

Thesis

\section{Degree Name}

Master of Science (MS)

\section{Program}

Biomedical Sciences

\section{Research Advisor}

Charles J. Russell, Ph.D.

\section{Keywords}

hPIV3, F protein, paramyxovirus

\section{Subject Categories}

Amino Acids, Peptides, and Proteins | Chemicals and Drugs | Diseases | Medical Cell Biology | Medical Sciences | Medicine and Health Sciences | Virus Diseases 


\title{
Regulation of the Human Parainfluenza Virus (hPIV3) Fusion Protein
}

\author{
A Thesis \\ Presented for \\ The Graduate Studies Council \\ The University of Tennessee \\ Health Science Center
}

\author{
In Partial Fulfillment \\ Of the Requirements for the Degree \\ Master of Science \\ The University of Tennessee
}

By

Amanda Ruth Chapman

December 2008 
Copyright (C) 2008 by Amanda Ruth Chapman All rights reserved 
For my mother who has always believed that I have infinite potential and who has encouraged me to reach that potential every day. 


\section{Acknowledgements}

There are several people deserving recognition for their roles in helping me to complete my degree. Dr. Russell, thank you for your guidance and support. The lessons I have learned under your watchful eye will last a lifetime. Laura, thank you a million times over for your patience, guidance, and friendship. Without you I would have given up on biotinylation long ago. Thank you for always encouraging me to keep going. Mark, thank you for always helping me maintain perspective and a sense of humor. Thank you to John Mason and Helori Gaude for helping me with the cloning and modeling that helped get my project off the ground. Special thanks to Matthew Frank for your countless hours answering my questions and your willingness to help at a moments notice. Your dedication is greatly appreciated. Darcie Miller, thank you for helping me get a good start on understanding computer modeling. Dr. Whitt and Dr. Naren, thank you for believing in me even when things were down to the wire. To my family and friends, thank you for your encouragement, your love, and especially your reassurance that I can do anything I put my mind to.

Special thanks to the American Lebanese Syrian Associated Charities (ALSAC) and the CIDC at St. Jude Children's Infection Defense Center for the funding to support my research. Thank you to the Hartwell Center and Protein Production Facility at St. Jude Children's Research Hospital for their technical support. 


\begin{abstract}
Paramyxoviruses include a number of important human pathogens, including measles virus, mumps virus, and the human parainfluenza viruses (hPIV) 1-4, as well as several animal pathogens, such as Sendai virus, Nipah virus and Hendra virus. The creation of effective drugs and vaccines against this family of viruses would play an important role in decreasing the prevalence of these viruses and contributing to the health of both humans and animals worldwide. The purpose of this work was to determine how the fusion $(F)$ protein is regulated with a focus on the heptad repeat $B(H R B)$ region of the $F$ protein located in the ectodomain, directly adjacent to the transmembrane domain. This region has been suggested to play important roles in the initiation of fusion (Gravel 2003) as well as in the formation of the final hairpin structure that drives fusion (Russell 2001). My investigation of the HRB region of the parainfluenza fusion (F) protein has been to characterize the structure of this domain in the pre-fusion form of the $F$ protein in order to better understand the role it plays in fusion. An understanding of how $\mathrm{F}$ protein conformational changes are regulated may lead to the creation of more effective therapies against paramyxoviruses in general. A crystal structure obtained from the pre-fusion PIV5 F protein (Yin 2006) reveals that the HRB domain is in a triple stranded coiled coil conformation. However, in order to obtain the structure, a trimerization domain was used for structure stabilization. It is not known if the trimerization domain influenced the resulting crystal structure. My research has investigated the structure of the HRB region by creating mutations in both the pre-fusion hPIV3 F protein and peptides derived from the HRB region. Although much work still remains, preliminary results are consistent with the HRB region of the hPIV3 F protein forming a triple stranded coiled coil in the pre-fusion conformation.
\end{abstract}




\section{Table of Contents}

Chapter 1. Introduction 1

Brief Overview of Paramyxoviruses 1

Changes in F Protein Conformation 2

The Heptad Repeat B (HRB) Region 2

Chapter 2. Materials and Methods $\quad 5$

Cell Culture $\quad 5$

Plasmids 5

Transient Expression of Viral Envelope Glycoproteins 5

$\begin{array}{ll}\text { Radioimmunoprecipitation } & 8\end{array}$

$\begin{array}{ll}\text { Transformation } & 8\end{array}$

Peptide Induction 9

Lysis of BL-21 CodonPlus(DE3)-RIPL Cells 9

Column Purification 9

Cleavage of Peptide Constructs with Factor Xa 10

$\begin{array}{ll}\text { Concentration of Peptides } & 10\end{array}$

Chapter 3. Regulation of Full-Length hPIV3 F Protein Expression 11

and Fusogenicity by Residues in HRB

Introduction $\quad 11$

Materials and Methods $\quad 11$

Mutagenesis and Subcloning pGEM3X Mutations into a pCAGGs Background 11

Total $\mathrm{F}_{0}$ Protein Expression 11

$\begin{array}{ll}\text { Cleavage Efficiency } & 12\end{array}$

Biotinylation of Surface F Protein $\quad 12$

Syncytia Assay for Cell-Cell Fusion $\quad 12$

Luciferase Reporter Gene Assay for Cell-Cell Fusion 13

Results $\quad 13$

Mutations in the HRB Region of the hPIV3 Ectodomain

Do Not Decrease Expression of the F Protein 13

Surface Expression of Mutant F Proteins Is Comparable to wt F 13

hPIV3 F Proteins Found on the Cell Surface Are Fusion Capable 16

Mutations Have Significant Effects on Cell-Cell Fusion 16

$\begin{array}{ll}\text { Discussion } & 21\end{array}$

Chapter 4. Construction and Solubilization of hPIV3 Peptides 25

Introduction $\quad 25$

$\begin{array}{ll}\text { Materials and Methods } & 27\end{array}$ 
Creation of Plasmids Containing the HRA and HRB Peptides

Solubilization of Peptides Using Decreasing Urea Concentrations

Solubilization of Peptides Using a Decrease in $\mathrm{pH}$

Solubilization of Peptides in a Low Salt and Low pH Solution 29

Results

HRA Purification

Solubility of HRBGC Peptides

Cleavage by Factor Xa

Concentration of Peptides 


\section{List of Figures}

Figure 1-1. Schematic of the Paramyxovirus F Protein 3

Figure 2-1. $\quad$ Primer Design $\quad 6$

Figure 3-1. $\quad$ hPIV3 $F_{0}$ Protein Expression 14

Figure 3-2. $\quad$ hPIV3 F Surface Protein as Determined by Surface Biotinylation

Figure 3-3. Cleavage of Mutant hPIV3 F Proteins $\quad 18$

Figure 3-4. Syncytia Assay for Cell-Cell Fusion $\quad 19$

Figure 3-5. $\quad$ Luciferase Reporter Gene Assay for Cell-Cell Fusion 20

Figure 3-6. Schematic of the Three Helix Bundle 22

Figure 3-7. Side Chain Interactions in Mutant S477K 24

Figure 4-1. Thermodynamic Potential of Mutations in the HRB

Region of hPIV3 26

$\begin{array}{lll}\text { Figure 4-2. } & \text { Peptide Constructs } & 28\end{array}$

Figure 4-3. Benzamidine Sepharose Column Purification of HRA 30

Figure 4-4. Solubilization of the HRBGC Peptide $\quad 31$

Figure 4-5. Cleavage of Peptides by Factor Xa 33 


\section{List of Abbreviations}

$\begin{array}{ll}\text { BME } & \text { Beta-mercaptoethanol } \\ \text { DMEM } & \text { Dulbecco's Modified Eagle's Medium } \\ \text { F } & \text { Fusion Protein } \\ \text { FXa } & \text { Factor Xa Protease } \\ \text { HN } & \text { Hemagglutinin Neuraminidase Protein } \\ \text { hPIV3 } & \text { Human Parainfluenza Virus 3 } \\ \text { HPLC } & \text { High-performance Liquid Chromatography } \\ \text { HRA } & \text { Heptad Repeat A } \\ \text { HRB } & \text { Heptad Repeat B } \\ \text { IPTG } & \text { Isopropyl } \beta \text {-D-1-thiogalactopyranoside } \\ \text { LB } & \text { Luria-Bertani (Broth or Agar) } \\ \text { MBP } & \text { Maltose Binding Protein } \\ \text { PBS } & \text { Phosphate Buffered Saline } \\ \text { pI } & \text { Isoelectric Point } \\ \text { PMSF } & \text { Phenylmethylsulphonyl Fluoride } \\ \text { RIPA } & \text { Radioimmunoprecipitation Assay Buffer }\end{array}$




\section{Chapter 1. Introduction}

\section{Brief Overview of Paramyxoviruses}

Paramyxoviruses include a number of important human pathogens, including measles virus, mumps virus, respiratory syncytial virus, and human parainfluenza viruses (hPIV) $1-4$, as well as several animal pathogens, such as Sendai virus, and newly emerging, highly pathogenic Nipah virus and Hendra virus. The interest in viruses composing this family has been due to their high infectivity (measles virus), high prevalence worldwide (the hPIVs), and their economic impacts on animal and poultry rearing (rinderpest virus and Newcastle disease virus). The impact of this family of viruses can be seen in the World Health Organization's attempt to eradicate measles as well as the push for vaccines protecting children against hPIV3, a pathogen that hospitalizes 30,000 children in the United States alone and is almost always fatal in those with immunodeficiencies [1].

Pathogens belonging to the family Paramyxoviridae are divided into subfamilies Paramyxovirinae and Pneumovirinae which are differentiated based on nucleocapsid structure, number of encoded proteins, and differences in attachment proteins. The subfamily Paramyxovirinae is further divided into five genera: Rubulavirus (Mumps), Avulavirus (Newcastle disease), Respirovirus (hPIV3, Sendai virus), Henipaviruses (Nipah virus, Hendra virus), and Morbillivirus (measles virus). The division of Paramyxovirinae genera is based on the presence or absence of neuraminidase activity and antigenic cross-reactivity [2].

All paramyxoviruses are enveloped, single-stranded, negative-stranded RNA viruses. The negative-stranded RNA genome serves two main functions including being a template for mRNA synthesis as well as being a template for synthesis of the positive antigenome strand. The antigenome strand is created only after mRNA synthesis and is essential in creating more negative stranded RNA for packaging into virions. Also included in the paramyxovirus structure are the nucleocapsid protein $(\mathrm{N})$, the phosphoprotein $(\mathrm{P})$, and the large protein $(\mathrm{L})$. The nucleocapsid protein is responsible for a variety of functions including interaction sites for assembly of the virion, and protection of the RNA genome from protease digestion [2]. The L protein functions as an RNA dependant RNA polymerase and interacts with the $\mathrm{P}$ protein which is important for activation of the enzyme complex and enhanced stability of the L protein [3].

The lipid envelope surrounding the virus is derived from the plasma membrane of the

host cell and contains two surface glycoproteins, an attachment protein ( $\mathrm{HN}, \mathrm{H}$, or $\mathrm{G})$ and a fusion (F) protein which mediates $\mathrm{pH}$ independent fusion of the viral and host cell membranes. For Rubulaviruses and Respiroviruses, the attachment glycoprotein is the hemagglutinin neuraminidase $(\mathrm{HN})$ protein which binds sialic acid receptors on host cell membranes and is necessary for the release of viral particles from infected cells. The binding of the $\mathrm{HN}$ protein to sialic acid is necessary for the activation of the $\mathrm{F}$ protein to cause fusion of the viral and cell membranes. To prevent cell agglutination, the $\mathrm{HN}$ also 
contains neuraminidase activity which cleaves sialic acid and allows the escape of budding viruses from the host cell membrane.

\section{Changes in F Protein Conformation}

The $\mathrm{F}$ protein of paramyxoviruses is a class I fusion protein. Class I proteins are defined by an $\alpha$-helical coiled coil structure and include proteins such as the influenza HA protein and HIV gp-41 protein. The $\mathrm{F}$ protein is initially expressed as an inactive $\mathrm{F}_{0}$ precursor which is subsequently cleaved intracellularly by the protease furin. The resulting metastable fusion-capable complex is composed of two disulfide linked subunits, a membrane distal $F_{1}$ subunit and a membrane proximal $F_{2}$ subunit. The $F$ protein also contains a hydrophobic fusion peptide, two 4-3 heptad repeat regions, and a transmembrane domain. Upon triggering by the $\mathrm{HN}$ protein, the $\mathrm{F}$ protein undergoes a series of conformational changes thought to include several distinct intermediates (Fig. 1-1). The molecular mechanism of triggering by HN remains unknown although there is evidence that the stalk of the HN protein directly interacts with the head of the $\mathrm{F}$ protein [4]. The first conformational change in the F protein occurs in HRB as an early fusion intermediate defined by the opening up of the triple stranded coiled coil conformation of HRB [5]. Based on the prefusion structure of PIV5 solved by Yin, et al. in 2006 [6] residues 443, 447, and 449 at the n-terminal end of the HRB region are important in altering the triggering capabilities of the F protein [7, 8]. Next, the HRA region refolds into a triple stranded coiled coil which propels the fusion peptide into the host cell membrane [5]. Previous studies in the HRA region show that residues in this area also affect the fusion capabilities of the F protein [9]. Finally the HRB region of the F protein swings up and binds in an antiparallel manner to HRA forming a six helix bundle bringing the viral and cell membranes to cause fusion [5].

\section{The Heptad Repeat B (HRB) Region}

Based on previous studies implicating the HRB region in the initiation of fusion [10] as well the role of HRB in the formation of the final fusogenic hairpin structure that drives fusion [5] the study of the HRB can be beneficial to the further understanding of paramyxovirus fusion. The uncleaved prefusion structure of PIV5 [6] and the post fusion structures of hPIV3 and NDV [11] provide a visual representation of HRB conformational changes and are important tools in furthering our knowledge. However, despite the importance of residues at the N-terminal region of HRB, very few experiments have explored the residues closest the transmembrane domain. In order to obtain a more accurate understanding of this area we chose hPIV3 for which the final fusogenic structure has been already solved. Questions about the HRB region arise from the methods used to obtain the prefusion structure of closely related PIV5. When Yin, et al. set out to determine the crystal structure for the prefusion structure of PIV5, they found that when the transmembrane domain was deleted they only obtained structures of the final fusogenic hairpin structure implicating the transmembrane 
A.

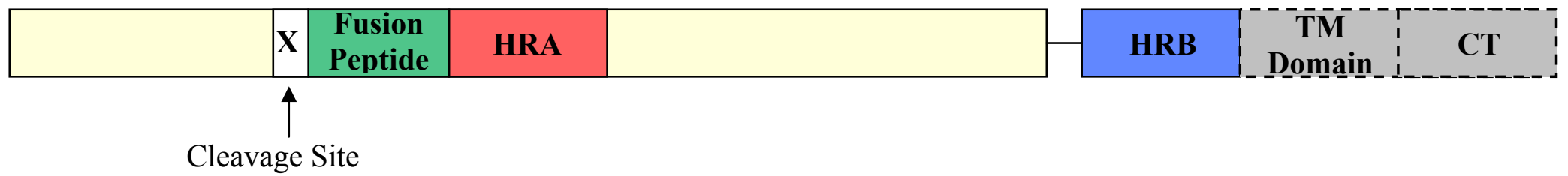

Host Cell Membrane

B.

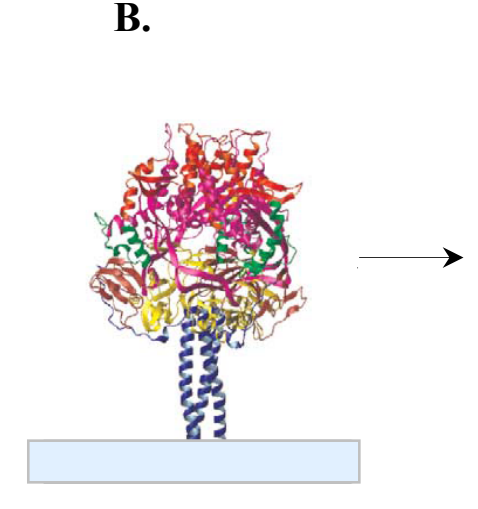

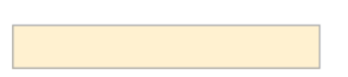

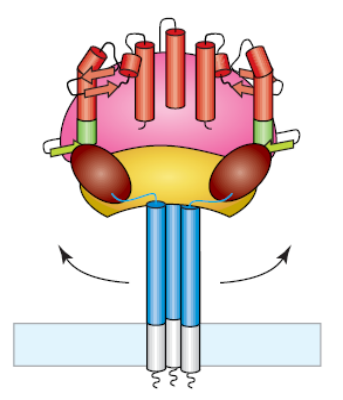

\section{Tost Mentrane}

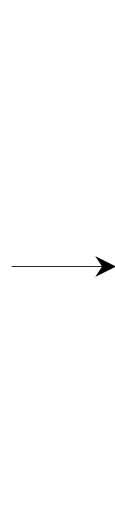

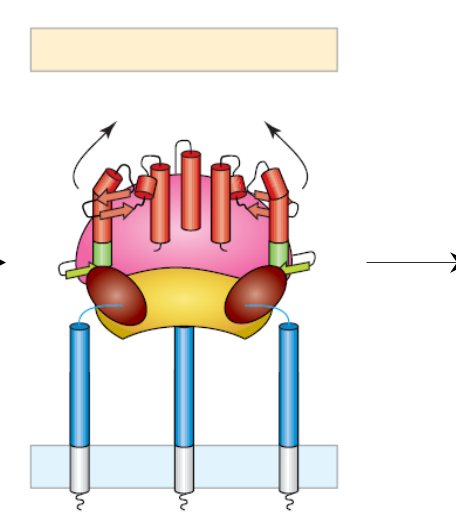

Viral Membrane

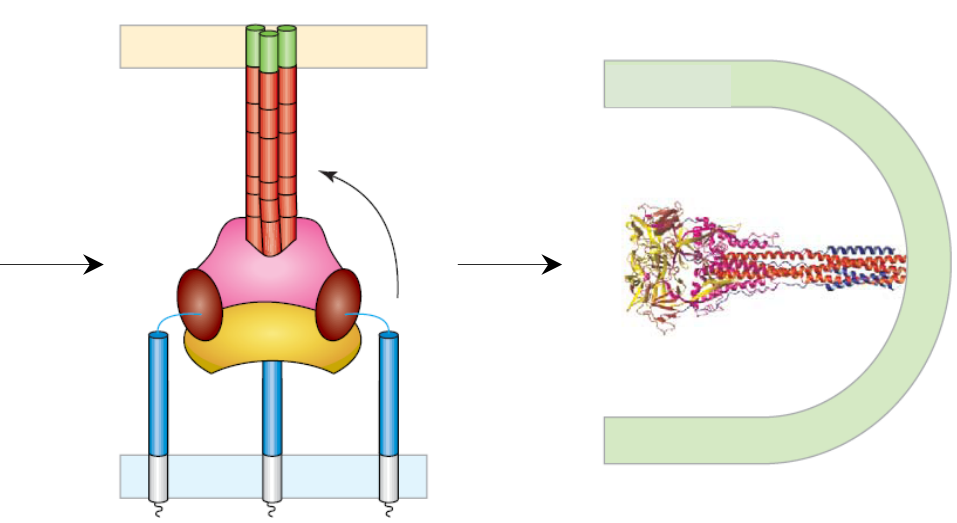

Figure 1-1. Schematic of the Paramyxovirus F Protein. (A) Structure of the $F$ protein. The intracellular site of cleavage of $\mathrm{F}_{0}$ into $\mathrm{F}_{1}$ and $\mathrm{F}_{2}$ subunits is represented by the $\mathrm{X}$. The fusion peptide (green), heptad repeat $\mathrm{A}$ (red), and heptad repeat $\mathrm{B}$ (blue) are also represented along with the transmembrane domain and cytoplasmic tail (gray, dotted line). (B) The series of conformational changes believed to lead to viral and host cell membrane fusion. Ribbon diagrams represent the pre-fusion PIV5 $\mathrm{F}_{0}[6]$ and the post-fusion hPIV3 F structure [11]. Conformational changes are based on biochemical studies $[5,7,8]$ and are represented here schematically. 
domain as important in the stabilization of the metastable prefusion form of the F protein. In order to stabilize the prefusion structure without hindering the crystallization process, a trimerization domain $(\mathrm{GCN} 4)$ was attached to the c-terminus of the HRB region in place of the transmembrane domain and cytoplasmic tail [6]. The results based on the crystal structure obtained by Yin has been the basis for our views on how the F protein functions and how it promotes viral and cell membrane fusion. Despite suggestions that a trimerization domain does not affect the HRB structure [6] many fundamental questions arise. Does the addition of a trimerization domain influence the secondary structure of the HRB region? Through studies based in HRB directly adjacent to the transmembrane domain we hope to study the previous model of the prefusion structure of the paramyxovirus F protein to determine role of the trimerization domain. Not only will these studies shed light on the true secondary structure of the HRB region, they will help us to answer questions about the initiation of fusion and increase our understanding on how to create effective treatments and vaccines against some of the world's most prominent viral pathogens. 


\section{Chapter 2. Materials and Methods}

\section{Cell Culture}

Monolayer cultures of Vero (ATCC CCl-81) cells, BHK-21 cells (ATCC CCL-10), and BSR-T7/5 cells [12] were grown in Dulbecco's Modified Eagle's Medium (DMEM) containing $10 \%$ fetal calf serum (FCS), $1 \%$ glutamine, $1 \%$ penicillin, and $1 \%$ streptomycin. To preserve the plasmid containing the $\mathrm{T} 7$ promoter, geneticin in a final concentration of $1 \mathrm{mg} / \mathrm{ml}$ was used to supplement BSR T7/5 cell media every other passage. BHK-21 cells were supplemented with 10\% tryptose phosphate broth. All cell lines were maintained at $37^{\circ} \mathrm{C}$ and $5 \% \mathrm{CO}_{2}$.

\section{Plasmids}

Primers were designed according to the recommendations of the QuickChange sitedirected mutagenesis kit (Stratagene) for creating point mutations in pGEM3X hPIV3 F plasmids [13] which have been described previously. Mutations of interest were chosen based on computer modeling completed by Helori Gaude and include S477A, S477K, N478D, N478K, and G485K. Mutants I484D, I484G, and G485A had been previously created in the pGEM3X background by Charles J. Russell. Primers for the introduction of single mutations extended at $10-22$ nucleotides on each side of the mutation of interest (Fig. 2-1). A list of primers used for mutagenesis can be found in Table 2-1.

Mutations in pGEM3X hPIV3 F plasmids were subcloned into the pCAGGs hPIV3 F plasmid previously described [14] or into the MBP plasmid pMAL - c2E (New England Biolabs, N8066S). All pGEM3X hPIV3 F plasmids inserts containing the mutation of interest were subcloned into pCAGGs hPIV3 F or pMAL-c2E plasmid vectors by digestion with ClaI and XhoI or BamHI and SalI respectively. The nucleotide sequences of all constructed plasmids was confirmed by the Hartwell Center of St. Jude Children's Research Hospital.

\section{Transient Expression of Viral Envelope Glycoproteins}

Monolayers of Vero cells (ATCC CCl-81) in six-well dishes (at 85\%-95\% confluence) were transiently transfected by using the Lipofectamine Plus Expression System (Invitrogen) with 1 - $2 \mu \mathrm{g}$ pCAGGs C243 F protein DNA, $1 \mu \mathrm{g}$ pCAGGs C243 HN protein DNA, or both. Transfected cells were incubated at $37^{\circ} \mathrm{C}$ for $2 \mathrm{hr}$. Transfection media was removed from the cells and DMEM containing $10 \%$ fetal calf serum and $1 \%$ glutamine was added. Cells were incubated for $16-18 \mathrm{hr}$ at $37^{\circ} \mathrm{C}$ and then treated as described in subsequent experiments. 


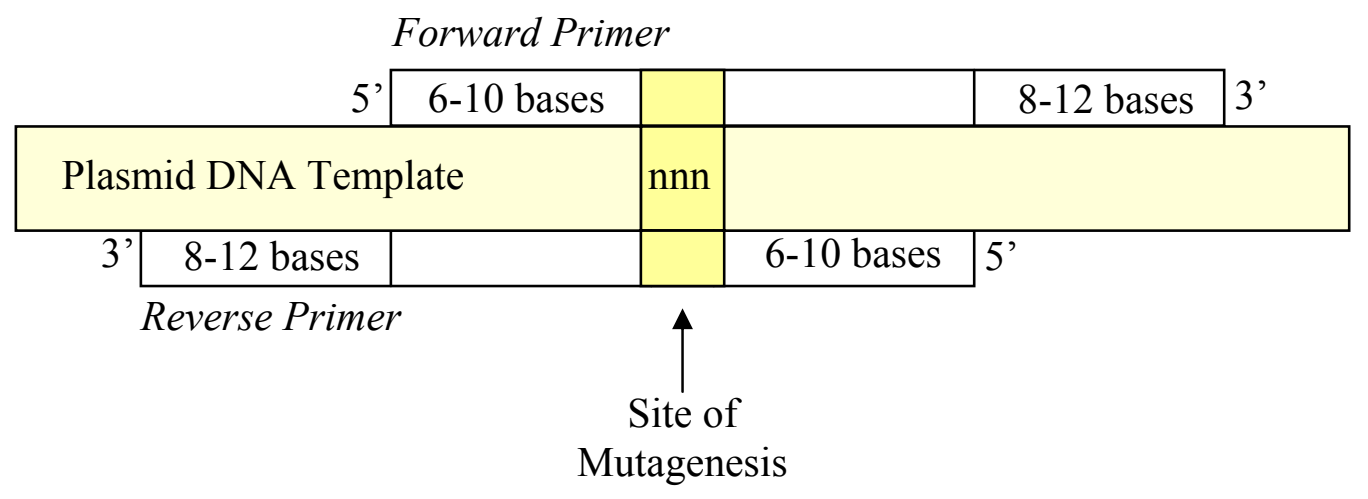

Figure 2-1. Primer Design. Primers for mutagenesis were designed using the template represented here. Forward and reverse primers were homologous to double stranded plasmid template DNA with the exception of the site of mutagenesis. 
Table 2-1. Primers Used in pGEM3X hPIV3 C243 F Mutagenesis.

\begin{tabular}{|c|c|c|}
\hline Mutation & Primer Name & Sequence $\left(5^{\prime}-3^{\prime}\right)$ \\
\hline \multirow{2}{*}{ S477A } & ARC1006 (Fwd) & ggataagaagggcaaatcaaaaactagattccattg \\
\hline & ARC1007 (Rev) & gtttttgatttgeccttcttatccattcttttgac \\
\hline \multirow[t]{2}{*}{ S477K } & ARC1008 (Fwd) & ggataagaaggaaaaatcaaaaactagattccattg \\
\hline & ARC1009 (Rev) & gtttttgatttttccttcttatccattcttttgactc \\
\hline \multirow[t]{2}{*}{ N478D } & ARC1000 (Fwd) & gataagaaggtcagaccaaaaactagattccattggaaattg \\
\hline & ARC1001 (Rev) & gaatctagtttttggtctgaccttcttatccattcttttgac \\
\hline \multirow[t]{2}{*}{ N478K } & ARC1014 (Fwd) & gataagaaggtcaaaacaaaaactagattccattggaaattg \\
\hline & ARC1015 (Rev) & gaatctagttttgttttgaccttcttatccattcttttgac \\
\hline \multirow[t]{2}{*}{ G485K } & ARC1004 (Fwd) & gattccattaaaaattggcatcaatctagcaccac \\
\hline & ARC1005 (Rev) & gatgccaatttttaatggaatctagtttttgatttg \\
\hline
\end{tabular}




\section{Radioimmunoprecipitation}

Vero cells expressing either wild type (wt) or mutant $\mathrm{F}$ proteins were maintained in methionine- and cysteine- free DMEM for $30 \mathrm{~min}$. Cells were then labeled for $15 \mathrm{~min}$ in $0.5 \mathrm{ml}$ methionine- and cysteine- free DMEM containing $20 \mathrm{mM}$ HEPES buffer ( $\mathrm{pH} 7.3$ ) and $50 \mu \mathrm{Ci}\left[{ }^{35} \mathrm{~S}\right]$ (Perkin Elmer). In order to allow the protein to reach the cell surface, the cells were then washed once with phosphate buffered saline (PBS) containing $0.1 \mathrm{~g} / \mathrm{L}$ magnesium chloride and $0.1 \mathrm{~g} / \mathrm{L}$ calcium chloride (PBS + ) and chased with $3 \mathrm{ml}$ of DMEM containing $2 \mathrm{mM}$ Methionine, $2 \mathrm{mM}$ cysteine, and $20 \mathrm{mM}$ HEPES buffer ( $\mathrm{pH}$ 7.3) for $120 \mathrm{~min}$. Samples were lysed with ice-cold radioimmunoprecipitation assay buffer (RIPA) containing $0.2 \mu \mathrm{g} / \mathrm{ml}$ aprotinin, $10 \mathrm{mM}$ iodoacetamide, and $1 \mathrm{mM}$ phenylmethylsulphonyl fluoride (PMSF). The lysate was spun at 67,000 x g for 15 minutes in an Optima TLX ultracentrifuge (Beckman Coulter) as described previously [15].

The supernatant was incubated on a nutator overnight (18 to 22 hours) at $4{ }^{\circ} \mathrm{C}$ with $7 \mu 1$ of A0028 rabbit anti-tail peptide polyclonal antibody. $60 \mu 1$ of Protein A Sepharose CL4B (GE Healthcare) suspended in a 50-50 slurry in $50 \mathrm{mM}$ Tris ( $\mathrm{pH} 7.0)$ was added to immune complexes for $1 \mathrm{hr}$ at $4^{\circ} \mathrm{C}$. Samples were washed three times with RIPA buffer containing $0.3 \mathrm{M} \mathrm{NaCl}$, three times with RIPA buffer containing $0.15 \mathrm{M} \mathrm{NaCl}$, and once with SDS wash II (5 mM NaCl, $1 \mathrm{M}$ Tris, $0.25 \mathrm{M}$ EDTA, pH 7.4). Samples were resuspended in $50 \mu 1$ of $4 x$ NuPAGE ${ }^{\circledR}$ SDS Sample Buffer (Invitrogen). The samples were then boiled for $5 \mathrm{~min}$, centrifuged in an Eppendorf microcentrifuge, and fractionated on a $12 \%$ NuPAGE Bis- Mini gel (Invitrogen).

Gels were stained for $1 \mathrm{hr}$ in SimplyBlue SafeStain (Invitrogen). Gels were then changed over into 1x Gel Drying Solution (BioRad) for $30 \mathrm{~min}$ and dried at $70^{\circ} \mathrm{C}$ for $1 \mathrm{hr}$ on a BioRad Gel Dryer. Visualization of protein bands were obtained using a Typhoon 9200 phosophoimager (GE Healthcare) and quantified using ImageQuant 5.2 software (Molecular Dynamics).

\section{Transformation}

To prevent codon bias leading to possible delayed translation or RNA degradation of hPIV3 F protein BL-21 CodonPlus(DE3)-RIPL cells (Stratagene) were used for transformation. The bacteria were thawed on ice and $100 \mu 1$ were aliquoted into prechilled $14 \mathrm{ml}$ polypropylene round-bottom tubes (Falcon). XL 10-Gold $\beta$ mercaptoethanol (Stratagene) was diluted 1:10 and $2 \mu \mathrm{l}$ was added to each $100 \mu \mathrm{l}$ aliquot of bacteria. The bacteria mix was incubated on ice for $10 \mathrm{~min}$ with gentle swirling in 2 min increments. Plasmid DNA (1-50 ng) was added to each tube containing BL-21 bacteria and the reaction was incubated for $30 \mathrm{~min}$ on ice. The reactions were then heatpulsed for $20 \mathrm{sec}$ in a $42^{\circ} \mathrm{C}$ water bath and immediately incubated on ice for $2 \mathrm{~min} .900$ $\mu 1$ of S.O.C. medium (Invitrogen) was added to each reaction followed by a $1 \mathrm{hr}$ incubation at $37^{\circ} \mathrm{C}$ with shaking. After incubation, $200 \mu \mathrm{l}$ of transformed bacteria were 
spread onto plates containing LB agar and ampicillin. Plates were incubated overnight at $37^{\circ} \mathrm{C}$.

\section{Peptide Induction}

A single bacterial colony was used to inoculate $10 \mathrm{ml}$ of LB broth containing $50 \mu \mathrm{g} / \mathrm{ml}$ of chloramphenicol and was incubated at $37^{\circ} \mathrm{C}$ with shaking overnight. After incubation the $10 \mathrm{ml}$ culture was pipetted into $500 \mathrm{ml}$ of LB broth without any selection antibiotics. The culture was incubated at $37^{\circ} \mathrm{C}$ with shaking and monitored for an O.D $D_{600}$ of 0.5 . To induce peptide production $100 \mu \mathrm{M}$ isopropyl $\beta$-D-1-thiogalactopyranoside (IPTG) was added to the culture at $37^{\circ} \mathrm{C}$ with shaking. Two hr post-induction the culture was spun down at $4^{\circ} \mathrm{C}$ for 15 minutes at $2,900 \mathrm{x}$ g on a Beckman Avanti J-251 refrigerated centrifuge. The pellet was weighed and kept at $-20^{\circ} \mathrm{C}$. The HRA peptide was induced separately by the Protein Production Facility at St. Jude Children's Hospital.

\section{Lysis of BL-21 CodonPlus(DE3)-RIPL Cells}

To extract peptides lysis buffer containing $20 \mathrm{mM}$ Tris and $200 \mathrm{mM} \mathrm{KCl}$ was added to pelleted BL-21 cells. Lysis buffer was added in volume twice the weight of the pellet. 5 $\mathrm{mM} \beta$-mercaptoethanol and $1 \mathrm{mM}$ PMSF were then added and the pellet was vortexed until completely resuspended. Cells were then sonicated with a VirSonic 60 (VirTis) for $2 \mathrm{~min}$ in $30 \mathrm{sec}$ intervals. Samples were spun down in an Eppendorf microcentrifuge for $30 \mathrm{~min}$ at $4^{\circ} \mathrm{C}$. The supernatant was collected and further centrifuged for $30 \mathrm{~min}$ at $27,000 \mathrm{x}$ g at $4^{\circ} \mathrm{C}$ on an Avanti J-251 centrifuge (Beckman).

\section{Column Purification}

Supernatant containing the peptide of interest was loaded into a Nickel (Ni) column washed once with 3 bed volumes of equilibration buffer containing $20 \mathrm{mM}$ Tris and 300 $\mathrm{mM} \mathrm{NaCl}$ and the flow through collected. To reduce non-specific binding the column was then washed once with a low imidazole buffer containing $20 \mathrm{mM}$ Tris, $300 \mathrm{mM}$ $\mathrm{NaCl}$, and $20 \mathrm{mM}$ imidazole. Each wash was 3 bed volumes and the flow through collected in $1 \mathrm{ml}$ fractions. To elute peptides from the column a high imidazole buffer containing $20 \mathrm{mM}$ Tris, $300 \mathrm{mM} \mathrm{NaCl}$, and $250 \mathrm{mM}$ imidazole was used and $1 \mathrm{ml}$ fractions collected. Peptides were visualized in a 16\% Tricine gel (Invitrogen) under reducing conditions and stained with Coomassie stain.

Peptide samples obtained from the Protein Production Facility of St. Jude Children's Research Hospital had been previously purified by affinity chromatography on a $\mathrm{Ni}$ column and cleaved with thrombin. To remove thrombin from the peptide solution to prevent sample degradation, peptides were loaded into Benzamidine Sepharose 6B (GE Healthcare) column and the flow through collected in $1 \mathrm{ml}$ fractions. The column was washed with 3 bed volumes of binding buffer containing $20 \mathrm{mM}$ Tris and $200 \mathrm{mM} \mathrm{NaCl}$ 
and collected in $1 \mathrm{ml}$ fractions. Fractions containing peptides were identified by visualization on a 16\% Tricine gel (Invitrogen) and stained with Coomassie stain.

\section{Cleavage of Peptide Constructs with Factor Xa}

Peptide samples were cleaved with Factor Xa protease (FXa) (New England Biolabs) to remove the His tag and thrombincleavge site from the $\mathrm{N}$ terminus of the peptide. FXa was added to samples in a 1 to 1 ratio of sample to FXa and incubated $16-18 \mathrm{hr}$ at $37^{\circ} \mathrm{C}$. An additional $250 \mu \mathrm{l}$ of FXa was added to samples in low $\mathrm{pH}$ solutions and the sample incubated at $37^{\circ} \mathrm{C}$ for another $16-18 \mathrm{hr}$. Cleaved samples were kept at $4^{\circ} \mathrm{C}$.

\section{Concentration of Peptides}

Due to the low concentration of peptide found in each fraction after column purification samples were concentrated in order to increase visualization and effectiveness of subsequent assays. Samples were loaded into $0.5 \mathrm{ml} 3,000 \mathrm{MWCO}$ Centrifugal Filter Devices (Millipore) and centrifuged for $1 \mathrm{hr}$ at $4{ }^{\circ} \mathrm{C}$ on an Eppendorf microcentrifuge. 


\section{Chapter 3. Regulation of Full-Length hPIV3 F Protein Expression and Fusogenicity by Residues in HRB}

\section{Introduction}

With the recent determination of the hPIV3 and closely related NDV post-fusion conformations [11, 16] and the PIV5 pre-fusion conformation [3] of the paramyxovirus $F$ protein, there have been valuable insights into how the $\mathrm{F}$ protein mediates viral and cell membrane fusion. Biochemical studies have characterized dramatic conformational changes occurring in the paramyxovirus $\mathrm{F}$ protein $[2,17,18]$ and additional studies have investigated residues directly adjacent to the HRB region which have been shown to be important in the formation of $\mathrm{F}$ fusion intermediates in PIV5 [4, 7]. However, HRB residues directly adjacent to the transmembrane domain remain largely unexplored but are key in determining F protein stability and the initiation of fusion.

Various studies have determined the interaction of the hemagglutinin neuraminidase $(\mathrm{HN})$ protein with the HRB region [9] and have explored the relationship between the triggering of the $\mathrm{F}$ protein and the conformational changes in HRB [2]. However, because the structure of the pre-fusion F protein has never been determined without the addition of a trimerization domain, there are only theories surrounding the triple stranded coiled coil conformation of the HRB region. Based on a series of computer generated models by Helori Gaude, mutations to destabilize the F protein and therefore initiate the conformational changes into the final fusogenic structure can be assessed and can therefore determine the structure of the HRB region adjacent to the membrane. Although determining structure is vital to this investigation, biochemical studies on peptides derived from this region are still underway while $\mathrm{F}$ ectodomain studies are largely complete. It is because of this that we begin our analysis with the hPIV3 F ectodomain and conclude with the peptide analysis. We hypothesize that the HRB region of the F protein is found in a triple stranded coiled coil conformation when in the native prefusion state.

\section{Materials and Methods}

Mutagenesis and Subcloning pGEM3X Mutations into a pCAGGs Background. To create point mutations primers were designed and PCR reactions set up as previously described in Chapter 2. The mutants I484D, I484G, and G485A in pGEM3X were created previously by Charles J. Russell, Ph.D. Full length F protein ectodomain sequences containing mutations of interest were subcloned into the pCAGGs hPIV3 F background [14] using ClaI and XhoI restriction sites.

Total $\boldsymbol{F}_{0}$ Protein Expression. 16 - 18 hours after transfection, Vero cells were ${ }^{35} \mathrm{~S}$ labeled for 10 minutes, washed twice using PBS +, and chased for 0 minutes. 
Radioimmunoprecipitation was carried out as described and protein expression was visualized and quantified as stated in Chapter 2.

Cleavage Efficiency. 16 - 18 hours after transfection, Vero cells were ${ }^{35} \mathrm{~S}$ labeled and chased as described in Chapter 2. $12 \% \beta$-mercaptoethanol was added to each sample before gel electrophoresis in order to break disulfide bonds between $F_{1}$ and $F_{2}$ and allow for better visualization on a 12\% Bis-Tris gel (Invitrogen).

Biotinylation of Surface F Protein. For cell surface biotinylation experiments, Vero monolayers in $6 \mathrm{~cm}$ diameter dishes (80-90\% confluence) were transfected as previously described. 16 - 18 hours post-transfection, Vero cells were washed twice using PBS +, radiolabeled, and chased for 120 minutes. Samples were then biotinylated twice for 15 minutes with EZ-Link Sulfo-NHS-SS-biotin (Pierce) in a concentration of $2 \mathrm{mg}$ per $1 \mathrm{ml}$ of PBS $+(\mathrm{pH} \mathrm{8.0})$ at $4{ }^{\circ} \mathrm{C}$. The cells were washed once with $\mathrm{PBS}+$ and once with $\mathrm{PBS}+$ ( $\mathrm{pH}$ 8.0) containing $50 \mathrm{mM}$ glycine to remove excess biotin. The cells were then radioimmunoprecipitated as described in Chapter 2 and incubated with $15 \mu$ l antibody [15].

After the addition of $120 \mu 1$ of Protein-A Sepharose and subsequent washes, the samples were resuspended in $100 \mu \mathrm{l}$ of $50 \mathrm{mM}$ Tris ( $\mathrm{pH} 7.4$ ) containing $0.5 \%$ SDS, vortexed, boiled for 5 minutes, and centrifuged for 1 minute at $14 \mathrm{~K}$ in an Eppendorf 5417R. The supernantant was then split into two $50 \mu$ fractions. One fraction represented total radiolabeled $\mathrm{F}$ protein and was kept at $4^{\circ} \mathrm{C}$ for direct loading into a $12 \%$ NuPAGE Bis- Mini gel (Invitrogen). $1 \mathrm{ml}$ of Streptavidin Agarose buffer ( $0.15 \mathrm{M}$ $\mathrm{NaCl}, 20 \mathrm{mM}$ Tris [pH 8.0], $5 \mathrm{mM}$ EDTA. 1\% Triton X, 0.2\% BSA) and $100 \mu 1$ of Streptavidin Agarose Resin in a 50/50 slurry (Thermo Scientific) was added to the second fraction which was incubated overnight on a nutator at $4^{\circ} \mathrm{C}$. The samples were then washed three times with RIPA buffer containing $0.3 \mathrm{M} \mathrm{NaCl}$, once with RIPA buffer containing $0.15 \mathrm{M} \mathrm{NaCl}$, and once with SDS wash II (5 mM NaCl, $1 \mathrm{M}$ Tris, $0.25 \mathrm{M}$ EDTA, pH 7.4).

Syncytia Assay for Cell-Cell Fusion. Monolayers of BHK-21 cells grown in 6-well plates were transfected with pCAGGs C243 F and pCAGGs C243 HN protein DNA as described previously. At 20 hours post-transfection cells were stained with Hema 3 solution (Fischer) according to manufacturer instructions. A Nikon D70 digital camera attached to a Nikon Eclipse TS100 inverted microscope was used to capture representative fields of each sample.

To quantify differences between mutants, the number of syncytia per field of view and the number of nuclei per syncytia formation were counted over 30 fields of view at 20x magnification on a Nikon TE300 Eclipse inverted microscope. Analysis of syncytia counts were completed using Microsoft Excel. 
Luciferase Reporter Gene Assay for Cell-Cell Fusion. To quantify membrane fusion a luciferase reporter gene assay was performed Vero cells were transfected with a T7 Luciferase Control DNA (Promega), pCAGGs C243 hPIV3 F, and pCAGGs C243 HN DNA as described in Chapter 2. 16-18 hours post-transfection BSR T7/5 cells were washed and spun down for 5 minutes at $1,800 \mathrm{rpm}$ in a Centra CL3 centrifuge (Thermo). The supernatant was removed, the BSR T7/5 cells were resuspended in DMEM media without antibiotic, and the BSR T7/5 cells were overlaid onto the Vero cells. Vero and BSR T7/5 cells were incubated together for 5 hours at $37^{\circ} \mathrm{C}$ in $5 \% \mathrm{CO}_{2}$ [4].

After incubation the cells were washed twice with PBS + and $500 \mu 1$ of Reporter Lysis Buffer (Promega) was added to each sample. Cells were then lysed by placing them at $20^{\circ} \mathrm{C}$ overnight and thawing them at room temperature the following day. The lysates were then spun down for 5 minutes at $14,000 \mathrm{k}$ in an Eppendorf $5417 \mathrm{R}$ at $4^{\circ} \mathrm{C}$ and $150 \mu 1$ of each sample was loaded into a 96 well plate. Luciferase activity was determined using Luciferase Assay Substrate (Promega) and a Veritas Microplate Luminometer (Turner Biosystems) per manufacturer's recommendations. All luciferase reporter gene assays were carried out in triplicate.

\section{Results}

\section{Mutations in the HRB Region of the hPIV3 Ectodomain Do Not Decrease} Expression of the F Protein. Computer modeling by Helori Gaude to determine the mutants of interest for this project focused only on the effect of the mutations in peptides derived from the full-length hPIV3 F protein but were not able to predict the effect these mutations would have on the overall expression and processing of the $\mathrm{F}$ protein. Computer models were created by inserting the amino acid sequence of hPIV3 into a structure based on the crystal structure obtained by Yin et al. for the closely related paramyxovirus PIV5 [3]. To determine the effects of mutations on total expression of the hPIV3 $\mathrm{F}$ protein the amount of uncleaved $\mathrm{F}_{0}$ was measured by a 10 minute radioimmunoprecipitation [15] with a rabbit anti-tail polyclonal antibody. $\mathrm{F}_{0}$ expression was analyzed by SDS-PAGE under denaturing conditions but in the absence of reducing agents. Mutations of both " $d$ " residues on the interior of the triple stranded coiled coil (S477 and I484) and "e" residues on the exterior of the structure (N478 and G485) in the HRB region of the hPIV3 F protein did not decrease expression although there was a noticeable increase in expression seen in mutants N478D and I484D (Fig. 3-1). A slight decrease was observed in S477A but expression was still seen at levels $90 \%$ of wild-type expression (Table 3-1).

Surface Expression of Mutant F Proteins Is Comparable to wt F. To determine if mutations would affect the cell surface expression of the F protein, cells were treated with the biotinylation reagent EZ-Link Sulfo-SS-biotin (Pierce) [15]. The cells underwent radioimmunoprecipitation with a rabbit anti-tail polyclonal antibody and pulldown with Streptavidin Agarose Resin (Thermo Scientific). Results indicate that mutant 
A

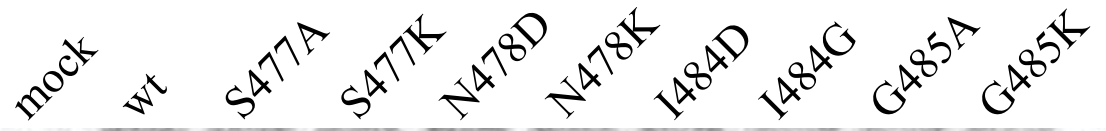

97

66

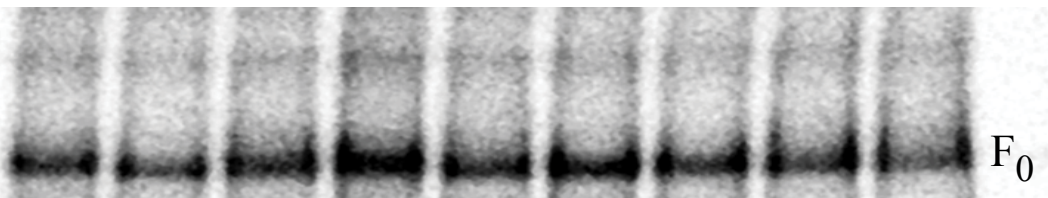

45

30

B

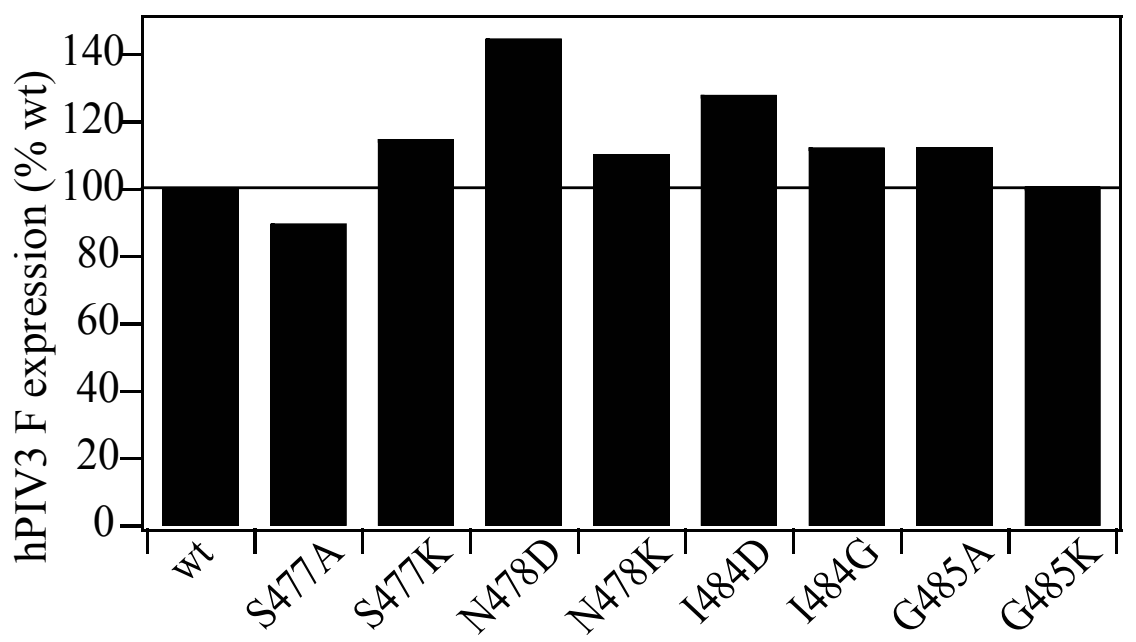

Figure 3-1. hPIV3 F 0 Protein Expression. (A) Vero cells expressing hPIV3 wild-type (wt) or mutant F proteins were labeled with $\left[{ }^{35} \mathrm{~S}\right]$ methionine for 10 minutes. Peptides were immunoprecipitated with a polyclonal antibody against the cytoplasmic tail of the $\mathrm{F}$ protein and analyzed on an SDS-PAGE gel under denaturing conditions and in the absence of a reducing agent. (B) Ratios of hPIV3 mutant F proteins as a percentage of wild-type. Solid line signifies $100 \%$ hPIV3 wild-type F expression. 
Table 3-1. Phenotypes of Wild-type and Mutant hPIV3 F Proteins ${ }^{\text {a }}$

\begin{tabular}{|c|c|c|c|c|c|c|c|c|}
\hline \multirow[b]{2}{*}{ hPIV3 F protein } & \multirow[b]{2}{*}{ HRB sequence } & \multirow{2}{*}{$\begin{array}{l}\text { Total } \\
\mathrm{F}_{0}^{\mathrm{b}}\end{array}$} & \multirow{2}{*}{$\begin{array}{l}\text { Cell Surface } \\
\text { Expression }^{c}\end{array}$} & \multirow{2}{*}{$\begin{array}{l}\text { Cleaved } \\
\mathrm{F}_{1} /\left(\mathrm{F}_{1}+\mathrm{F}_{0}\right)^{\mathrm{d}}\end{array}$} & \multicolumn{2}{|c|}{ Syncytia $^{\mathrm{e}}$} & \multirow{2}{*}{$\begin{array}{l}\text { Membrane Fusion } \\
\left.\quad \text { (Luciferase }^{\mathrm{h}}\right)\end{array}$} & \multirow{2}{*}{$\begin{array}{l}\text { Expected } \\
\text { Phenotype }^{\mathrm{i}}\end{array}$} \\
\hline & & & & & Syncytia/Field ${ }^{\mathrm{f}}$ & $\begin{array}{c}\text { Syncytial } \\
\text { Nuclei/Field }\end{array}$ & & \\
\hline wild-type (wt) & SNQKLDSIGN & 100 & 100 & 0.40 & 6.1 & 63.8 & $100 \pm 11$ & - \\
\hline S477A & $A \ldots \ldots$ & 90 & 96 & 0.47 & 8.4 & 89.1 & $127 \pm 13$ & destabilize \\
\hline S477K & K....... & 115 & 146 & 0.55 & 5.7 & 40.5 & $31 \pm 7$ & little / no effect \\
\hline N478D &.$D \ldots \ldots$ & 145 & 132 & 0.43 & 6.8 & 73.4 & $126 \pm 13$ & destabilize \\
\hline N478K &.$K \ldots \ldots$ & 110 & 150 & 0.53 & 10.6 & 107.3 & $124 \pm 1$ & destabilize \\
\hline I484D & $\ldots \ldots$. . . & 128 & 101 & 0.46 & 6.8 & 50.0 & $67 \pm 14$ & stabilize \\
\hline $\mathrm{I} 484 \mathrm{G}$ & $\ldots \ldots$ G. & 112 & 92 & 0.48 & 5.6 & 49.0 & $39 \pm 7$ & little / no effect \\
\hline G485A & $\ldots \ldots$ A. & 112 & 172 & 0.43 & 8.7 & 91.8 & $122 \pm 11$ & destabilize \\
\hline G485K & $\ldots \ldots \ldots$ & 101 & 132 & 0.50 & 9.4 & 88.3 & $97 \pm 21$ & stabilize \\
\hline
\end{tabular}

a hPIV3 F proteins expressed from pCAGGS DNA in Vero cells.

b Total $\mathrm{F}_{0}$ expressed after $10 \mathrm{~min}$ of $\left[{ }^{35} \mathrm{~S}\right]$ methionine labeling. Data is normalized to wild-type hPIV3 F.

c Cell surface expression determined by biotinylation. Data is normalized to wild-type hPIV3 F.

d Cleavage efficiency of hPIV3 F protein after $10 \mathrm{~min}$ of $\left[{ }^{35} \mathrm{~S}\right]$ methionine labeling and 2 hour chase.

e Cell-cell fusion as determined by syncytia assay.

f Average number of syncytia (fusion of 3 or more nuclei) per field of view at 20x magnification. Reported numbers represent 30 fields of view.

g Number of nuclei found in syncytia per field of view. Reported numbers represent 30 fields of view.

$\mathrm{h}$ Cell-cell fusion as determined by luciferase reporter assay. Data is normalized to wild-type hPIV3 F. The reported error indicates standard deviations from four triplicate experiments.

i Expected phenotype in HRB peptides based on computer modeling by Helori Gaude. Models created using Swiss Model and minimized using the AMBER program. 
hPIV3 F proteins S477A, I484D, and I484G show surface expression similar to expression seen in wt hPIV3 F. The other 5 mutants (S477K, N478D, N478K, G485A, and $\mathrm{G} 485 \mathrm{~K}$ ) show large increases in surface expression ranging from 132\% (S477A and $\mathrm{G} 485 \mathrm{~K}$ ) to $172 \%$ (G485A) of wt surface expression (Fig. 3-2, Table 3-1). Results suggest that mutations are comparable to wt with respect to amount of protein found on the cell surface and may even stabilize the F protein in some cases allowing the protein to be found in greater quantities on the cell surface.

hPIV3 F Proteins Found on the Cell Surface Are Fusion Capable. Before the hPIV3 F protein reaches the cell surface, it is cleaved intracellularly by the protease furin. This cleavage is necessary to convert the inactive $\mathrm{F}_{0}$ precursor into a fusion capable complex formed by disulfide linked $F_{1}$ and $F_{2}$ [19]. To assess efficiency of cleavage of the hPIV3 F protein, a radioimmunoprecipitation with a 15 minute ${ }^{35} \mathrm{~S}$ pulse and a 120 minute chase was performed. Cleavage efficiency was determined as the amount of $F_{1}$ divided by total $F\left(F_{1}+F_{0}\right)$ since the $F_{2}$ subunit was not visible on an SDS-PAGE gel. Results show that all mutants are cleaved in similar ratios to $\mathrm{F}$ wt. Despite high surface expression of several mutant hPIV3 $\mathrm{F}$ proteins, both $\mathrm{F}$ wt and mutant $\mathrm{F}$ proteins showed cleavage efficiencies of only $40 \%$ to $55 \%$ (Fig. 3-3, Table 3-1). However, this is most likely due to the fact that the samples were whole cell lysates containing both surface and intracellular $F$ proteins. The antibody pulling down both cleaved $F_{1}$ and $F_{2}$ surface proteins and uncleaved precursor $\mathrm{F}_{0}$ proteins still being processed intracellularly would account for the higher presence of $\mathrm{F}_{0}$.

Mutations Have Significant Effects on Cell-Cell Fusion. To determine the effects of the mutations on the fusogenicity of the hPIV3 F protein, Vero cells were transfected with both hPIV3 mutant F DNA and hPIV3 HN DNA, fixed, and stained 20 hours later to identify cell-cell fusion. Results from the syncytia assay show that despite similarities in expression and intracellular processing, mutations in the HRB region have visible effects on cell-cell fusion. Mutations S477A and N478K have noticeably larger syncytia created from the fusion of numerous cells while mutant $\mathrm{S} 477 \mathrm{~K}$ shows little syncytia formation containing fewer fused nuclei (Fig. 3-4). Since syncytia resulting from the expression of mutant $\mathrm{F}$ proteins showed differences in number and nuclei per syncytia, counts for both were conducted over 30 fields of view to more accurately compare mutation effects. Results confirm more syncytia consisting of more nuclei in mutants S477A and N478K as well as in the G485 mutants. As expected, mutants S477K, and I484D showed both lower syncytia counts with fewer nuclei (Table 3-1).

To achieve a more quantitative comparison between hPIV3 F mutants, a luciferase reporter gene assay was performed. Vero cells were transfected with a T7 Luciferase Control DNA (Promega), pCAGGs C243 hPIV3 F, and pCAGGs C243 HN DNA and overlaid with BSR cells constitutively expressing T7 polymerase. Cell-cell fusion of triplicate samples was measured by the amount of luciferase activity detected (Fig. 3-5). Results confirm the increase in fusogenicity of mutants S477A, N478K, and G485A and a decrease in fusogenicity of mutants S477K and I484D. Despite minor differences, 
A

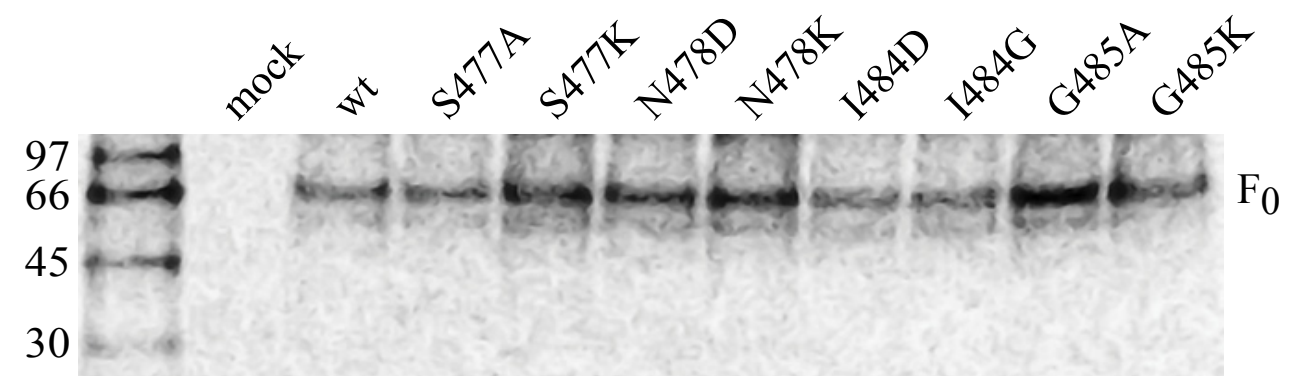

$\mathbf{B}$

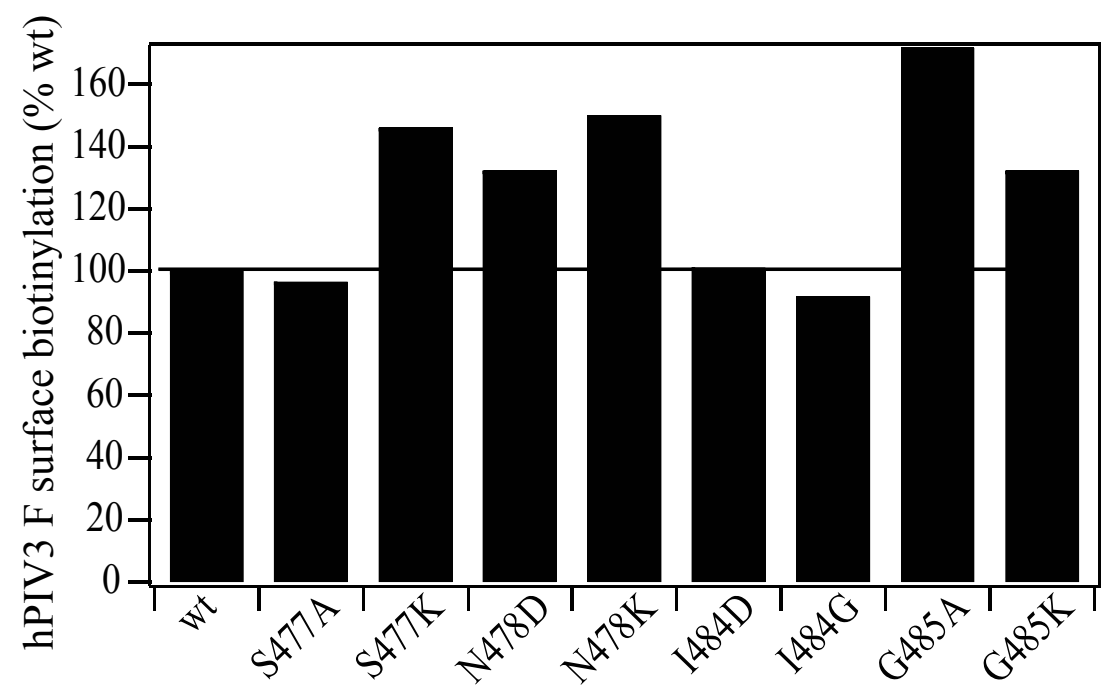

Figure 3-2. hPIV3 F Surface Protein as Determined by Surface Biotinylation. (A) Vero cells expressing hPIV3 wild-type (wt) or mutant F proteins were labeled with $\left[{ }^{35} \mathrm{~S}\right]$ for 15 minutes and chased for 2 hours. Cells were then biotinylated twice for 15 minutes each. Samples were immunoprecipitated with a polyclonal antibody against the cytoplasmic tail of the F protein and incubated with Protein A Sepharose overnight at $4^{\circ} \mathrm{C}$. Next day, samples were washed and biotinylated hPIV3 F protein was pulled down using Streptavidin. Samples were run on a SDS-PAGE gel under denaturing conditions but in the absence of reducing agents. (B) Ratios of surface biotinylation as a percentage of wt. Solid line signifies $100 \%$ hPIV3 wild-type (wt) biotinylation. 
A

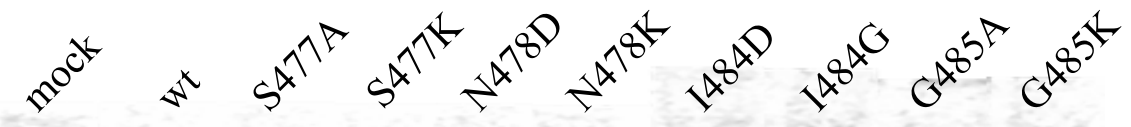

97

66

45

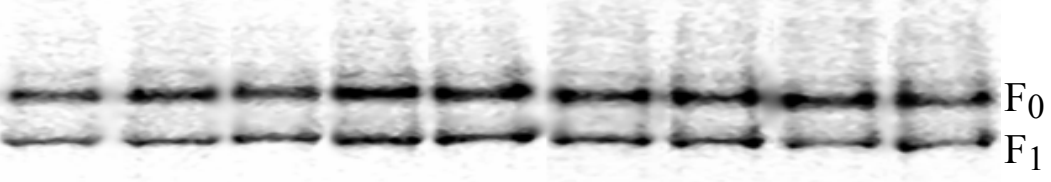

30

B

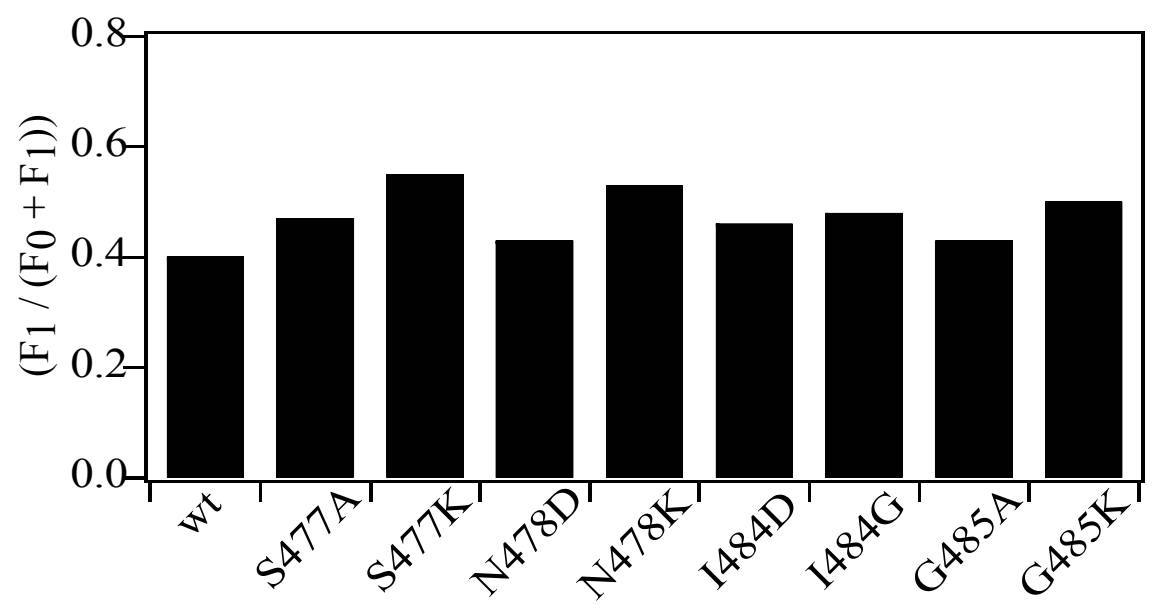

Figure 3-3. Cleavage of Mutant hPIV3 F Proteins. (A) Vero cells expressing hPIV3 $\mathrm{F}$ wild-type (wt) or mutant $\mathrm{F}$ proteins were labeled with $\left[{ }^{35} \mathrm{~S}\right]$ methionine for 10 minutes and chased for 2 hours. F proteins were immunoprecipitated with a polyclonal antibody against the cytoplasmic tail of the F protein and analyzed on a SDS-PAGE gel under reducing conditions. (B) Ratios of cleaved $F$ proteins. The intensities of the $F_{0}$ and $F_{1}$ bands from $A$ were quantified and the fraction of cleaved $F_{1}$ was calculated by dividing $\mathrm{F}_{1}$ by total $\mathrm{F}$. $\mathrm{F}_{2}$ protein was not observed in this assay 

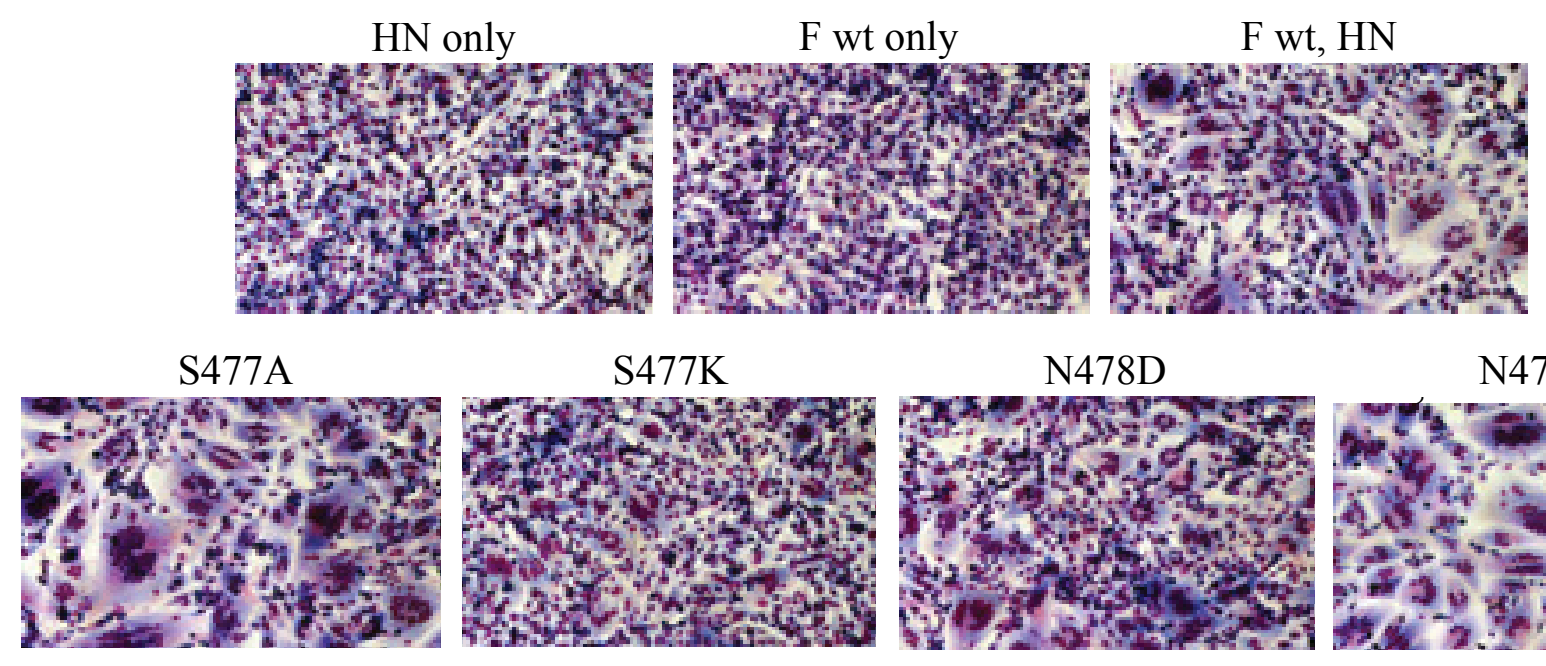

S477K

N478D
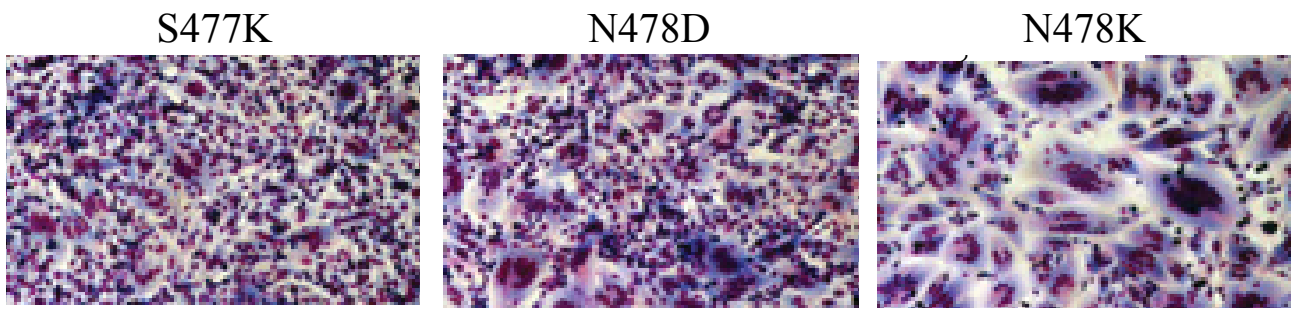

I484D

I484G

G485A

G485K
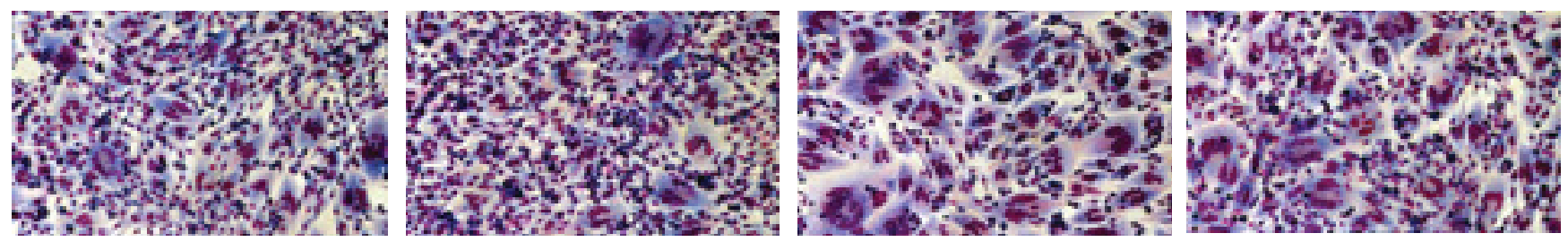

Figure 3-4. Syncytia Assay for Cell-Cell Fusion. Cell-cell fusion of BHK cells expressing wild-type (wt) or mutant F hPIV3 protein and hPIV3 HN protein. 20 hours post-transfection were stained with Hema 3 solution (Fischer) according to manufacturer instructions. Representative fields were captured on a Nikon Eclipse TS100 inverted microscope. Samples transfected with HN only or F wt only represent negative controls with no syncytia formation. 


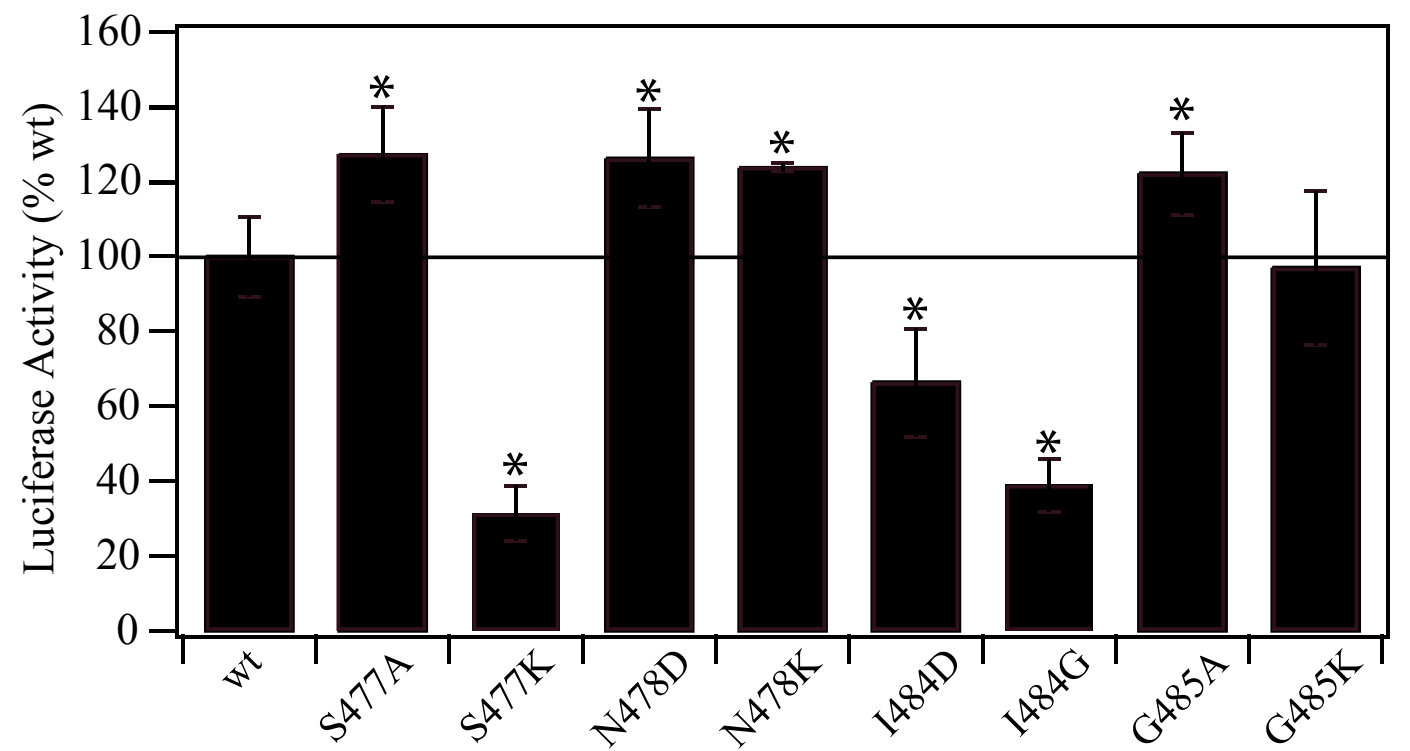

Figure 3-5. Luciferase Reporter Gene Assay of Cell-Cell Fusion. Cell-cell fusion of Vero cells transfected with luciferase T7 DNA and expressing wild-type (wt) or mutant F hPIV3 protein and hPIV3 HN protein. 16 hours post-transfection Vero cells were overlaid with BSR T7/5 cells expressing T7 polymerase for 5 hours at $37^{\circ} \mathrm{C}$. Reported luciferase activity was normalized to wt. Asterisks indicate a significant difference from wild-type as determined by the Student's t-test $(\mathrm{P} \leq 0.05)$. Luciferase data represents four sets of triplicate experiments. Solid line signifies $100 \%$ hPIV3 wild-type cell-cell fusion. 
results from the luciferase reported gene assay generally confirm observations made in the syncytia fusion assay.

\section{Discussion}

Studies investigating the effects of mutations in the HRB region of the hPIV3 F protein have proved to be relatively consistent with results obtained through computer modeling. In mutations such as S477A, N478D, N478K, and G485A expected to destabilize the HRB region of the $\mathrm{F}$ protein, total expression and cleavage are seen at levels similar to wt but there is an increase in fusogenicity. An increase in fusogenicity is expected from destabilizing mutations because by making interactions in the HRB region weaker, the protein would have a greater tendency to move into its lower energy, final fusogenic form and increase the amount of cell-cell fusion seen in both syncytia and luciferase reporter gene assays. However, with the exception of S477K, all the observed destabilizing mutants show an increase in cell surface expression of the $\mathrm{F}$ protein which may account for increased cell-cell fusion. To further investigate these mutants and determine the effect of a higher surface expression, a DNA titration assay could be performed to compare levels of transfected DNA to cell-cell fusion as determined by the luciferase reported gene assay. Transfection of differing amounts of DNA will determine if the increase in fusion is due to a destabilization of the pre-fusion $\mathrm{F}$ protein structure or simply due to an increase in the number of fusion proteins found on the cell surface.

Similarly, the mutation I484D, which lies on the interior of the triple stranded coiled coil at position 'd' (Fig. 3-6), was expected to stabilize the F protein and was characterized by similar expression, cell surface expression, and cleavage as well as a decrease in cell-cell fusion in both syncytia and luciferase assays. The mutation of a nonpolar isoleucine residue to an acidic aspartic acid residue may stabilize the F protein in its native structure by creating strong interactions with basic residue K480 on an adjacent coil. Interactions between these two residues would create strong enough interactions to promote the pre-fusion conformation of the $\mathrm{F}$ protein, causing a decrease in the formation of the final fusogenic form of the protein and therefore a decrease in the amount of cell-cell fusion observed. However, the second mutant expected to stabilize the HRB triple stranded coiled coil structure showed very little difference from the wt F protein. The mutation $\mathrm{G} 485 \mathrm{~K}$ was expected to stabilize the pre-fusion F structure according to the thermodynamic potentials obtained through computer modeling but instead showed expression, cleavage, and cell-cell fusion levels similar to wt. Despite reported increase in the number of syncytia per field and the number of syncytial nuclei per field, the luciferase assay reports cell-cell fusion levels similar to those reported in wt. This discrepancy can be explained by taking into consideration the position of residue 485. Due to residue 485 being located at an ' $\mathrm{e}$ ' position, the side chains of the residue would be interacting primarily with solvent molecules as opposed to adjoining amino acid side chains and therefore would play little or no part in the stability of the F protein as a whole. 


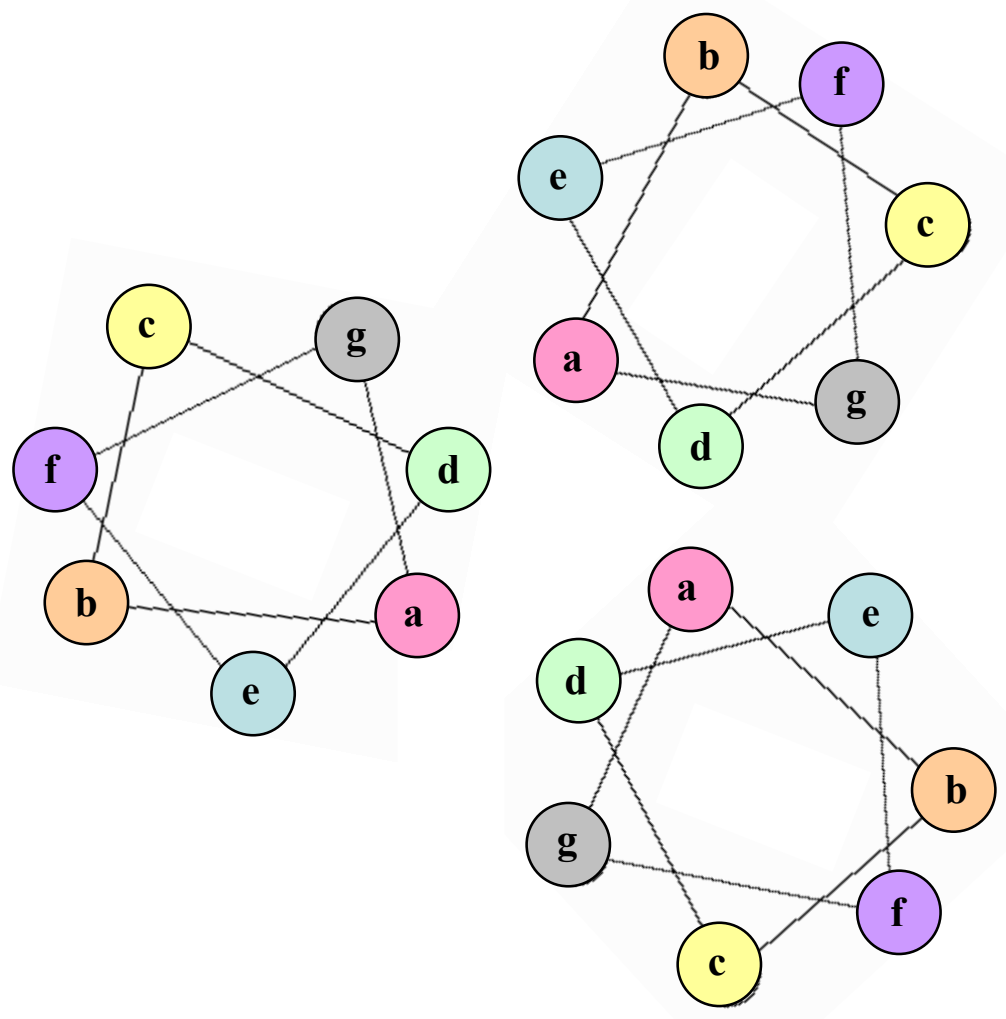

Figure 3-6. Schematic of the Three Helix Bundle. To visualize the placement of residues within the three-helix bundle the above model was created. Residues ' $a$ ' and ' $d$ ' are found on the interior hydrophobic surface of the triple stranded coiled coil conformation, while residues ' $b$ ', 'c', 'e', ' $f$ ', and ' $g$ ' show less side chain interactions and have a lesser effect on bundle stability. 
Finally, two mutations were chosen as having little or no effect on the stability of the F protein as determined by modeling and derived thermodynamic potentials. However, both mutations I484G and S477K showed increased stabilization as determined by cellcell fusion assays. The first mutation, $\mathrm{I} 484 \mathrm{G}$, is located at a ' $\mathrm{d}$ ' position and therefore directly influences the packing of the amino acid side chains within the triple stranded coiled coil. By removing isoleucine and replacing it with a glycine, which has a significantly smaller side chain, internal residues may be able to pack tighter and therefore increase the energy needed to separate the three helix bundle at the initiation of fusion. Alternatively, mutation $\mathrm{S} 477 \mathrm{~K}$, also located at a 'd' position, replaces an interior serine with the much larger side chain of lysine. According to the computer models generated by Helori, there are very few differences in the number of possible Vanderwaals interactions between the original serine at position 477 and the lysine mutation. However, the length and flexibility of the lysine side chain create a hydrogen bond with asparagine 478 which would contribute to the stability of the pre-fusion conformation of the F protein and result in decreased cell-cell fusion (Fig. 3-7). In addition, the models show the insertion of one lysine side chain straight into the middle of the three helix bundle. There is a possibility that this residue is able to fill the interior cavity of the three helix bundle and therefore exclude solvent molecules, also resulting in an increase in stability of the pre-fusion F protein conformation. Due to the flexible nature of the lysine residue, further modeling may contribute to our understanding of this mutant. Since the created models only show one possible position of the lysine residues, alternate models could be helpful in further determining additional interactions contributing to the stabilization of the pre-fusion F protein.

Based on the information obtained in our studies, we believe the HRB region of the hPIV3 $\mathrm{F}$ protein is found in a triple stranded coiled coil conformation in the pre-fusion structure. My analyses of the interactions responsible for changes in F protein stability are based on models representing only the HRB region, with the assumption that these models represent the HRB region in the full length F protein as well. The creation of full-length $\mathrm{F}$ protein models would be another useful tool in verifying the side chain interactions observed in the HRB models. Although there are some differences between estimated thermodynamic potentials and actual stabilities observed in F protein mutants, further analysis of amino acid side chain interactions in computer models can account for observed differences. The creation of more complex computer models which take into consideration differences in side chain positioning can be further investigated to further understand experimental results. 


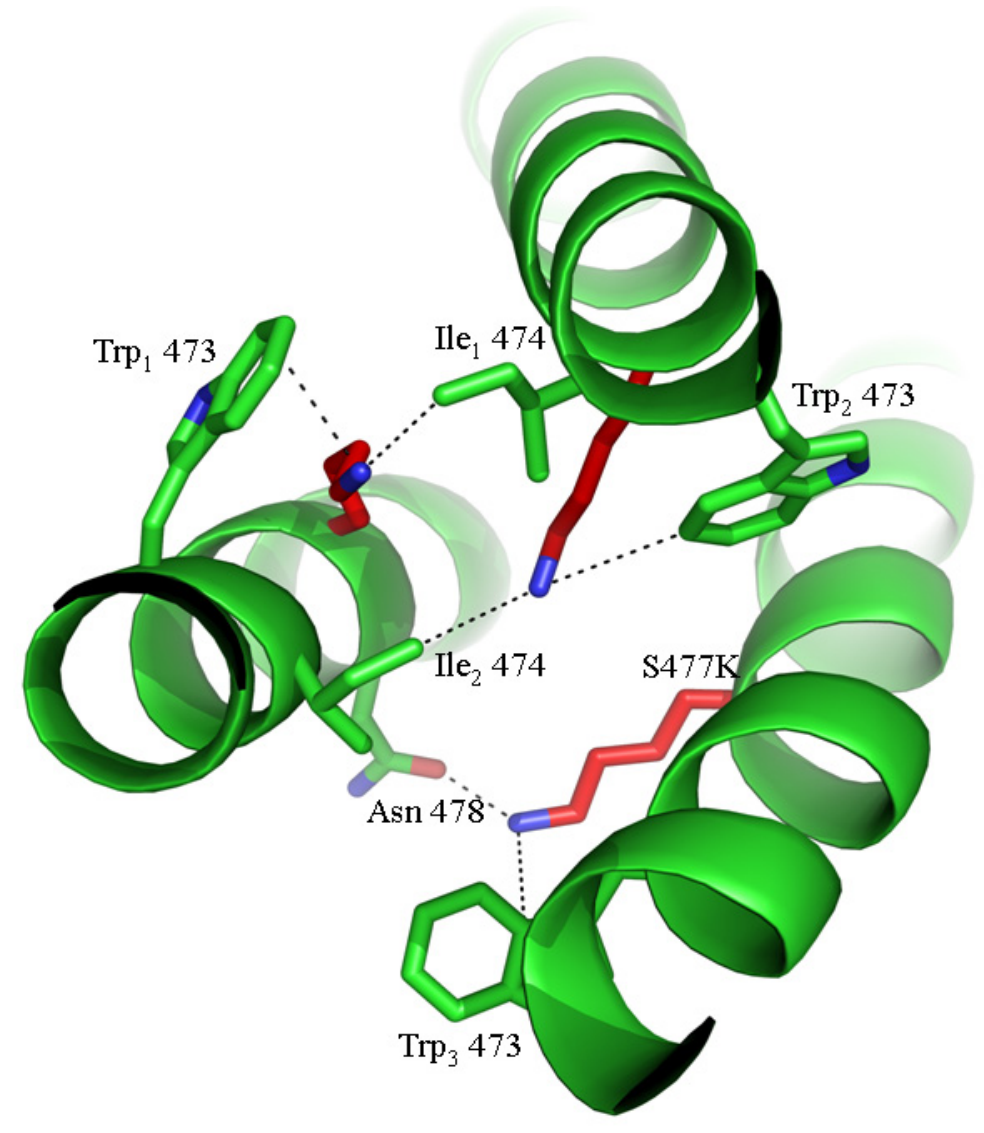

Figure 3-7. Side Chain Interactions in Mutant S477K. Using previously generated models, possible Vanderwaals interactions and hydrogen bonding was assessed. Lysine's flexibility allows at least 2 Vanderwaals interactions per residue and allows for a hydrogen bond between the lysine at position 477 and adjacent asparagine 478. Mutated residues $\mathrm{S} 477 \mathrm{~K}$ are represented in red. 


\section{Chapter 4. Construction and Solubilization of hPIV3 Peptides}

\section{Introduction}

Biochemical and structural studies have shown that the fusion $(\mathrm{F})$ protein undergoes a series of conformational changes. Two distinct structures have been solved for the $\mathrm{F}$ protein by Yin et. al. The structure of the human parainfluenza virus 3 (hPIV3) F protein shows both the heptad repeat A (HRA) and the heptad repeat B (HRB) in a hairpin conformation, a hallmark of the post-fusion conformation [11]. On the other hand, the recently solved structure of the parainfluenza virus 5 (PIV5) F protein is believed to represent the native conformation of the $\mathrm{F}$ protein [3].

Studies have confirmed the dramatic conformational changes in the heptad repeat A (HRA) and heptad repeat $\mathrm{B}(\mathrm{HRB})$ regions of the paramyxovirus $\mathrm{F}$ protein $[2,3,4,15]$. However, several biochemical observations need to be reconciled with the structural data. For example, in previous studies HRA peptides have been found to spontaneously fold into a triple stranded coiled coil conformation [20] while peptides derived from the HRB region have been found primarily a random coil conformation [20, 21]. However, when HRB is placed in a solution with HRA the two peptides bind in an antiparallel manner to form a six helix bundle which drives the fusion of the viral and cell membranes [20, 22]. These observations suggest that the HRB region is unstable and requires the assistance of other domains to remain structured. In the pre-fusion PIV5 F structure the HRB region is found in a triple stranded coiled coil conformation [6]. Due to the tendency of the $F$ protein to refold into its final fusogenic form when the transmembrane domain directly adjacent to the HRB region is deleted [11], some structural studies have proceeded by attaching a trimerization domain to the c-terminus of the HRB region in an effort to stabilize the pre-fusion conformation [11, 23, 24]. Despite suggestions that the trimerization domain has little or no effect on the formation of the HRB secondary structure [6] question still arise regarding the conformation of the HRB region. Is the HRB region actually found in a triple stranded coiled coil structure? Is the secondary structure of the HRB a result of the attached trimerization domain?

To determine the effect of a trimerization domain on HRB conformation a series of peptides assays were suggested. Computer modeling by a previous student, Helori Gaude, allowed a number of mutations to be chosen based on their ability to disrupt or stabilize the three helix bundle of the HRB region as determined by an estimated thermodynamic potential (Fig. 4-1) from modeling programs Swiss-Model and AMBER. The creation of an HRB peptide attached to a trimerization domain, and carrying various mutations will allow us to assess the effect of the trimerization domain on secondary structure. Mutations meant to disturb the formation of a three helix bundle and resulting in expected stabilization or destabilization of the three helix bundle will confirm the nature of the HRB region. We propose that the addition of a trimerization domain does not alter HRB conformation and that the HRB region is indeed found in a triple stranded coiled coil conformation. 


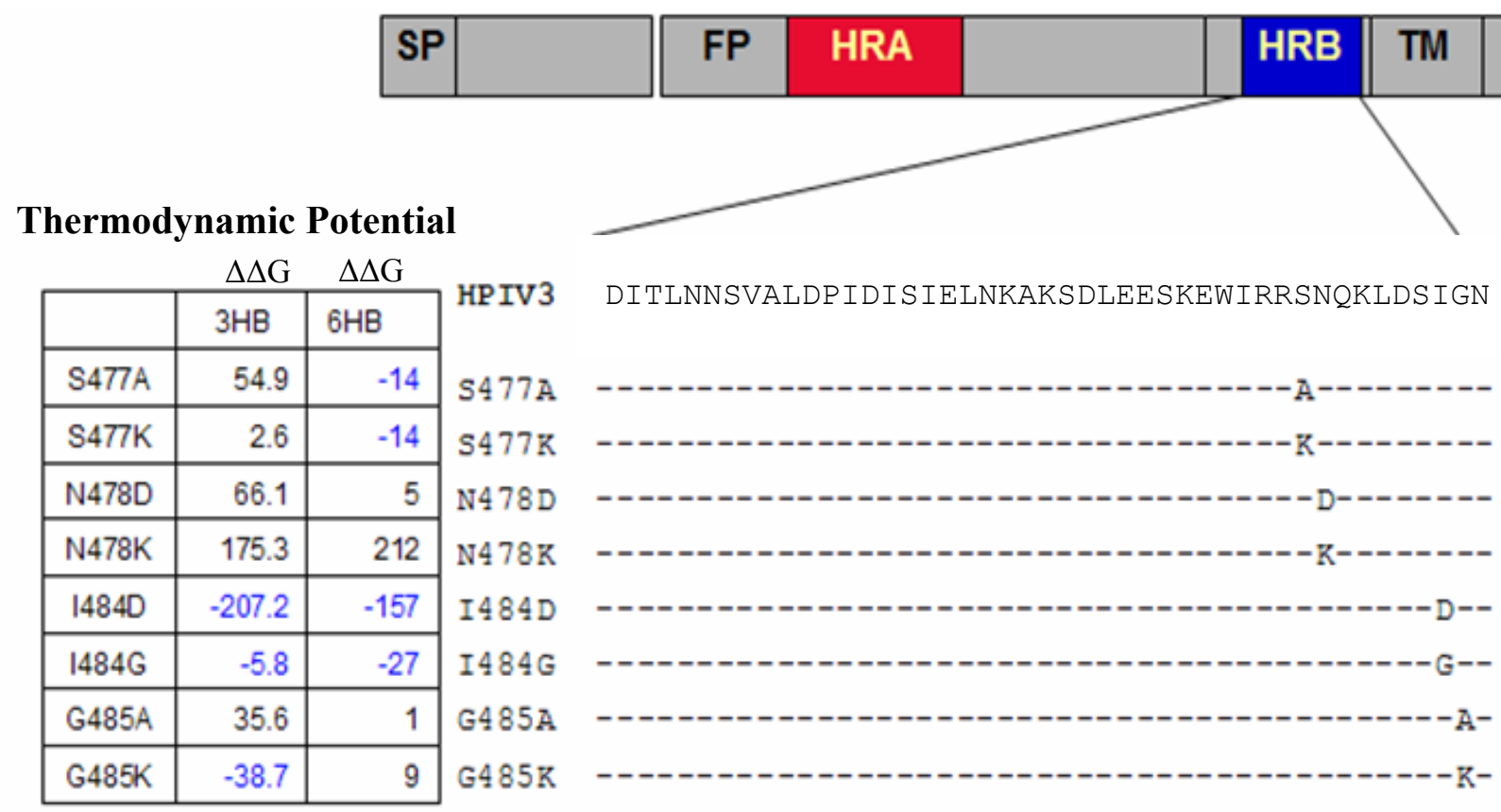

\section{Expected phenotype:}

destabilize native structure cause little change

destabilize native structure destabilize native structure stabilize native structure cause little change destabilize native structure stabilize native structure

Figure 4-1. Thermodynamic Potential of Mutations in the HRB Region of hPIV3. Thermodynamic calculations for mutations in the HRB region were completed by Helori Gaude using the Swiss-Model program and were minimized using the AMBER program. Mutations were chosen based on the ability to either destabilize or stabilize a three helix bundle of the HRB peptide. Control mutations S477K and I484G were expected to cause little or no change in HRB stability. 


\section{Materials and Methods}

Creation of Plasmids Containing the HRA and HRB Peptides. Residues 136 to 191 from the hPIV3 F protein were initially subcloned from the pGEX4TI hPIV3 N56 plasmid (provided by the Lamb lab) into a pET15b background by Helori Gaude using BamHI and SalI restriction sites. Point mutations were generated by Helori Gaude using the QuickChange site-directed mutagenesis kit (Stratagene) (data not shown). The hPIV3 F HRBGC pET15b plasmid was subcloned by John Mason from a puc vector synthesized by Blue Heron Biotechnology, Inc. into a pET15b background using BamHI and SalI restriction sites to create the HRB peptide. This construct contains residues 454 to 486 from the hPIV3 F protein and a GCN4 domain. Both constructs contain an N terminal His tag, thrombin cleavage site, and Factor Xa (FXa) cleavage site (Fig. 4-2). Finally, residues 454 to 486 from the hPIV3 F protein were subcloned into pMAL - c2E (New England Biolabs, N8066S) using BamHI and SalI restriction sites. Sequences of plasmid constructs were confirmed by the Hartwell Center of St. Jude Children's Research Hospital.

Solubilization of Peptides Using Decreasing Urea Concentrations. Insoluble peptides were those found in the pellet as opposed to the supernatant after induction and lysis. The pellet containing the insoluble peptide was resuspended in $7 \mathrm{M}$ urea. Urea was added in volume twice the weight of the pellet and $5 \mathrm{mM} \beta$-mercaptoethanol ( $\beta \mathrm{ME})$ was added. The solution was vortexed until completely resuspended and then loaded into a 3,500 MWCO Slide-A-Lyzer Casette (Pierce) for dialysis. Every $16-18 \mathrm{hr}$ the casette was changed over into solution containing less urea. Solutions for dialysis included 150 $\mathrm{mM} \mathrm{NaCl}, 5 \mathrm{mM} \beta \mathrm{ME}$, and either $7 \mathrm{M}, 3 \mathrm{M}, 1 \mathrm{M}$, or $0 \mathrm{M}$ urea. Dialysis occurred at $4^{\circ} \mathrm{C}$.

Solubilization of Peptides Using a Decrease in pH. Limited success with previous solubilization methods led to an alternate approach based on recommendations from the QIAexpressionist handbook (Qiagen). Pellets were resuspended in lysis buffer and then spun down for $30 \mathrm{~min}$ at $27,000 \mathrm{xg}$ at $4^{\circ} \mathrm{C}$ in an Optima L-90K ultracentrifuge (Beckman). The supernatant was removed and the pellet was resuspended in a non-ionic detergent buffer containing $20 \mathrm{mM}$ Tris, $200 \mathrm{mM} \mathrm{KCl}$, and $0.5 \%$ Triton-X100 and spun down. The supernatant was removed and the pellet was resuspended a third time in a solution containing $10 \mathrm{mM}$ Tris, $100 \mathrm{mM} \mathrm{NaH}_{2} \mathrm{PO}_{4}$, and $7 \mathrm{M}$ urea at an initial $\mathrm{pH}$ of 8.0 and spun down. The supernatant was loaded into a Ni column and washed with once (3 bed volumes) with solutions containing $10 \mathrm{mM}$ Tris, $100 \mathrm{mM} \mathrm{NaH}_{2} \mathrm{PO}_{4}$, and $7 \mathrm{M}$ urea with each subsequent solution dropping in $\mathrm{pH}(\mathrm{pH} \mathrm{8.0,6.3,} \mathrm{5.9,} \mathrm{and} \mathrm{4.5).} \mathrm{Flow} \mathrm{through}$ was collected from all washes in $1 \mathrm{ml}$ fractions. Fractions containing peptide of interest were then dialyzed from $7 \mathrm{M}$ urea to $0 \mathrm{M}$ urea using a $5 \mathrm{mM} \mathrm{KCl}$ solution including 5 $\mathrm{mM} \beta \mathrm{ME}$. 


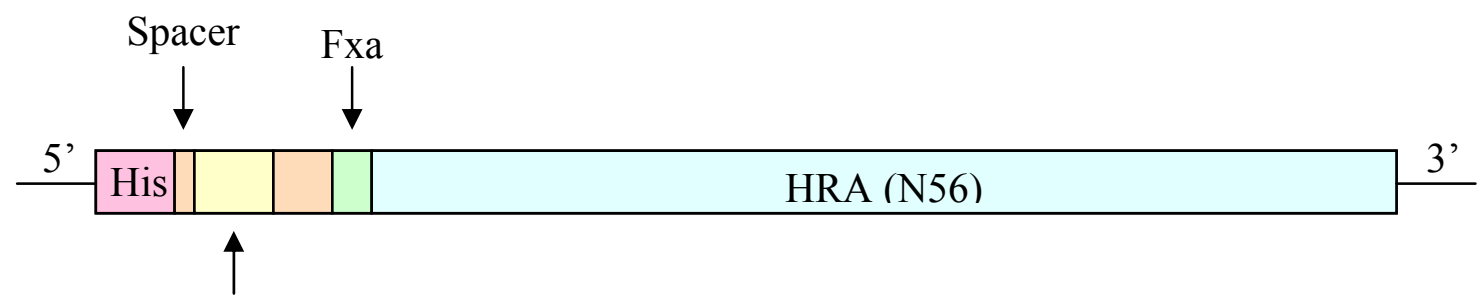

Thrombin

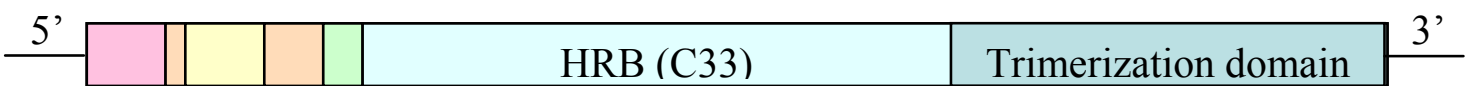

Figure 4-2. Peptide Constructs. hPIV3 F HRB and HRA sequences subcloned initially into pET15b vectors. Constructs contain a six amino acid histidine tag (His), a thrombin cleavage site (Thrombin), and a FXa cleavage site (FXa) attached to the $n$-terminal end of the heptad repeat region. The HRB peptide also contains a 23 amino acid trimerization domain attached to its $\mathrm{C}$-terminus. 
Solubilization of Peptides in a Low Salt and Low pH Solution. The third method of solubilization included a decrease in urea concentration accompanied by a low salt concentration and acetate to lower the $\mathrm{pH}$ of the solution. Fractions obtained by washes with low pH solutions through the Ni column underwent dialysis in $20 \mathrm{mM}$ acetate (Sigma) solutions ( $\mathrm{pH} 5.0$ ) including $5 \mathrm{mM} \mathrm{KCl}, 5 \mathrm{mM} \beta \mathrm{ME}$, and decreasing concentrations of urea ( $7 \mathrm{M}, 3 \mathrm{M}, 1 \mathrm{M}$, and $0 \mathrm{M})$. Solubilization of peptides was confirmed by ultracentrifugation for $1 \mathrm{hr}$ at $100,000 \mathrm{x}$ g and $4^{\circ} \mathrm{C}$ in an Optima L-90K ultracentrifuge (Beckman).

\section{Results}

HRA Purification. Since the HRA region of hPIV3 has been shown to be a promoter of HRB secondary structure when incubated together $[20,22]$ we wanted to create and purify a HRA peptide to examine the effects of mutations in the hPIV3 F HRB region on formation of the six helix bundle. The HRA peptide was created by the Protein Production Facility of St. Jude Children's Hospital where it was purified through a nickel column and cleaved with thrombin. In order to remove the thrombin and prevent peptide degradation, samples were run though a Benzamidine Sepharose 6B (GE Healthcare) column which contains p-aminobenzamidine, a synthetic inhibitor of serine proteases such as thrombin. Samples were collected and visualized on a $16 \%$ Tricine gel (Invitrogen). Resulting gels show a peptide band running at the expected $8.8 \mathrm{kDa}$ (Fig. 4-3) although the presence of additional bands suggest further purification will be needed to determine the effect of mutations in HRB and their ability to interact with HRA to form a six helix bundle.

Solubility of HRBGC Peptides. To assess the secondary structure of the hPIV3 HRB region initial experiments were carried out only on the hPIV3 $\mathrm{F}$ wt peptide until a successful protocol could be established. BL-21 CodonPlus (DE3)-RIPL cells were transformed by heat-pulse with a plasmid containing the HRB sequence and a trimerization domain (HRBGC) and induced with IPTG (Fig. 4-4A). Despite the appearance of small amounts of HRBGC peptide after purification through a Ni column, the majority of the peptide was found to be in pellet samples suggesting that the peptide remained within the BL-21 CodonPlus (DE3)-RIPL cell membrane and is therefore insoluble (Fig. 4-4C).

Previous studies on the ability of urea to reversibly denature and solubilize peptides $[25,26]$ prompted the use of decreasing urea concentrations to solubilize the peptide and then allow refolding without aggregation. After induction and lysis, the remaining pellet containing the insoluble peptide was resuspended in a $7 \mathrm{M}$ urea solution under reducing conditions. Peptides in $7 \mathrm{M}$ urea and $150 \mathrm{mM} \mathrm{NaCl}$ underwent dialysis into solutions containing lower urea concentrations. Precipitate was seen when the peptide solution was put into a $1 \mathrm{M}$ urea dialysis solution. Despite the lower urea concentration, subsequent assays needed to determine HRB secondary structure would require a 


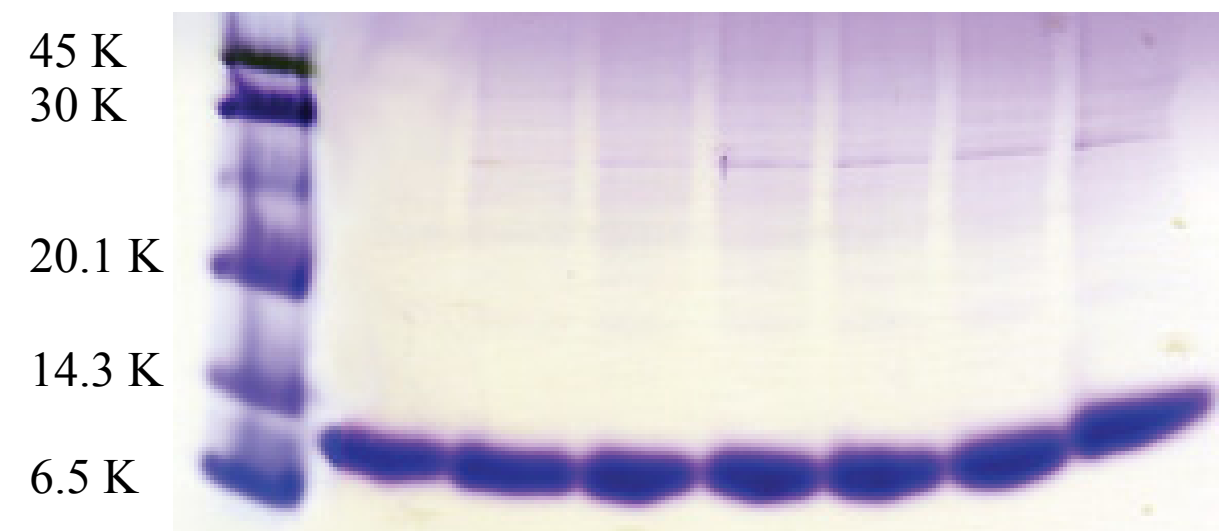

Figure 4-3. Benzamidine Sepharose Column Purification of HRA. Thrombin cleaved HRA peptides were run through a Benzamidine Sepharose 6B (GE Healthcare) column to remove excess thrombin. Visualization on a $16 \%$ Tricine gel (Invitrogen) shows purity of HRA after column purification. Each column represents a $1 \mathrm{ml}$ fraction. 
A.

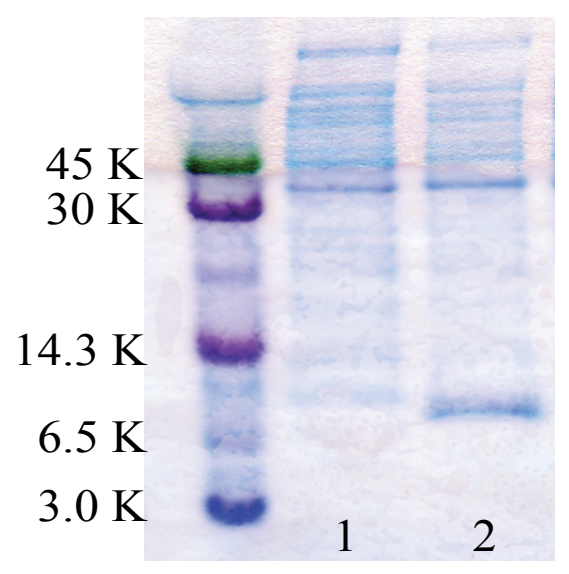

B.

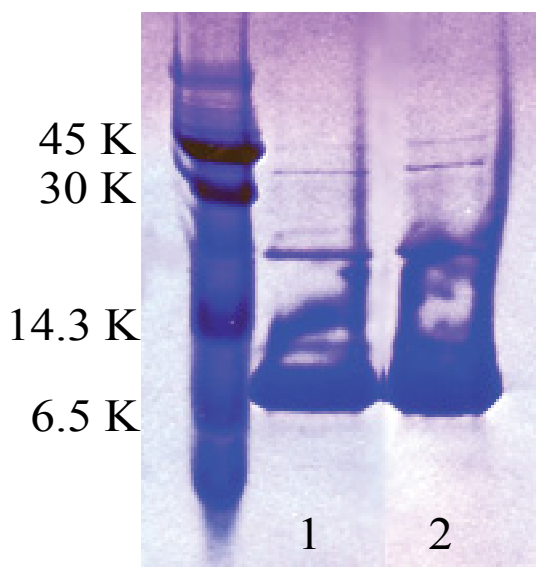

C.

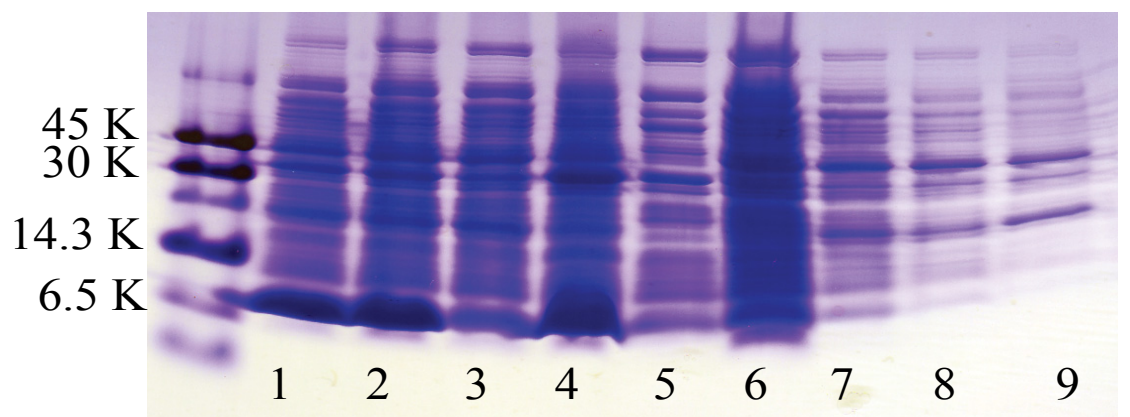

D.

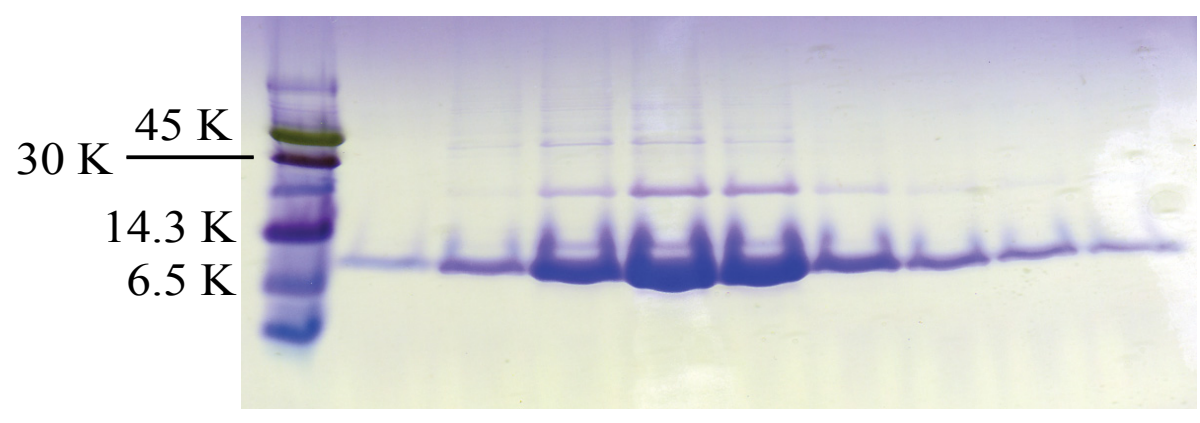

Figure 4-4. Solubilization of the HRBGC Peptide. (A) pET15b plasmids containing the hPIV3 F HRB sequence with an attached trimerization domain were transformed into BL-21 CodonPlus(DE3)-RIPL cells and induced with $100 \mu \mathrm{M}$ IPTG. Cells showed an increase in peptide production (lane 2) as opposed to an un-induced control (lane 1). (B) HRBGC peptides solubilized under low $\mathrm{pH}$ and low salt conditions were analyzed before (lane 1) and after ultracentrifugation (lane 2) to verify solubility. (C) Visualization of the HRBGC peptide after induction. Lanes 1 and 2 represent samples taken before cell lysis. Lanes 3 and 4 represent the supernatant and pellet samples after cell lysis. Lanes 5-9 represent flow through samples after Ni purification. (D) Fractions of HRBGC peptide after dialysis into a low $\mathrm{pH}(5.0)$ and low salt $(5 \mathrm{mM} \mathrm{KCl})$ solution and purification through a Ni column. Lanes represent soluble HRBGC fractions after passage through the column and collection in $1 \mathrm{ml}$ samples. 
complete absence of urea and therefore further exploration into methods for peptide solubilization were necessary.

Based on evidence that protonation of charged residues $(H, R, K, D$, and $E)$ increases solubility of aggregate peptides [27] dialysis of aggregate HRBGC peptides in low $\mathrm{pH}$ solutions was considered. The HRBGC peptide has 33\% charged residues and therefore may be good candidate for solubilization via protonation. Methods of solubilization and purification via changes in $\mathrm{pH}$ were per instructions in the QIAexpressionist handbook (Qiagen). Insoluble peptides were resuspended in a $7 \mathrm{M}$ urea solution at $\mathrm{pH} 8.0$ and then loaded into a Ni column. The column was washed with buffers containing $7 \mathrm{M}$ urea and decreasing $\mathrm{pH}$ values. The fractions containing the majority of peptide appeared as expected at $\mathrm{pH} 4.5$ and included noticeably less non-specific peptides as well as being aggregate free (Fig. 4-4D). However, many of the subsequent assays would require the peptides to be solubilized in a urea free solution. Attempts to bring the peptides back to urea free conditions via dialysis in a low $\mathrm{pH}$ buffer were unsuccessful.

In a third attempt to find correct solubilization conditions acetate was used to maintain a low $\mathrm{pH}$ and the salt concentration was reduced from $150 \mathrm{mM}$ to $5 \mathrm{mM}$. Dialysis was used to move the peptides from a solution containing $7 \mathrm{M}$ urea to one containing no urea at $\mathrm{pH}$ 5.0. Peptides remained soluble throughout dialysis and solubility was confirmed with ultracentrifugation (Fig. 4-4B). In a low salt and low $\mathrm{pH}$ solution peptides remained soluble as demonstrated by the absence of precipitate seen in the samples.

Cleavage by Factor $\mathbf{X a}$. In order to prevent inhibition of peptide secondary structure, the additional His tag and thrombin cleavage site were removed by proteolytic cleavage by FXa. Despite confirmation of the proper FXa cleavage site by sequence analysis, visualization of cleavage of the HRA peptide was minimum (Fig. 4-5A) although a gel shift could be seen suggesting cleavage had occurred.

An additional $250 \mu \mathrm{l}$ of FXa was added to the HRBGC peptide sample based on the appearance of a precipitate assumed to be the FXa. The appearance of precipitate can be explained by the 4.9 to 5.2 isolelectric point (pI) of FXa which suggests that FXa has less solubility in the range of $\mathrm{pH} 4.9$ to 5.2. The precipitate was confirmed to be FXa as opposed to the HRBGC peptide by visualization on an SDS-PAGE gel (Fig. 4-5B). Despite the increase in precipitate seen after the addition of FXa there was no decrease in the amount of peptide seen on the gel. These results confirm that the precipitate was the consequence of the FXa being in a low $\mathrm{pH}$ solution and not aggregation of the HRBGC peptide.

Concentration of Peptides. Samples of HRBGC peptide resulting from column purification had lower concentrations of peptide per fraction and therefore would need to be concentrated in order to effectively use them for subsequent purification assays such as high-performance liquid chromatography (HPLC) where they would be further diluted. 
A

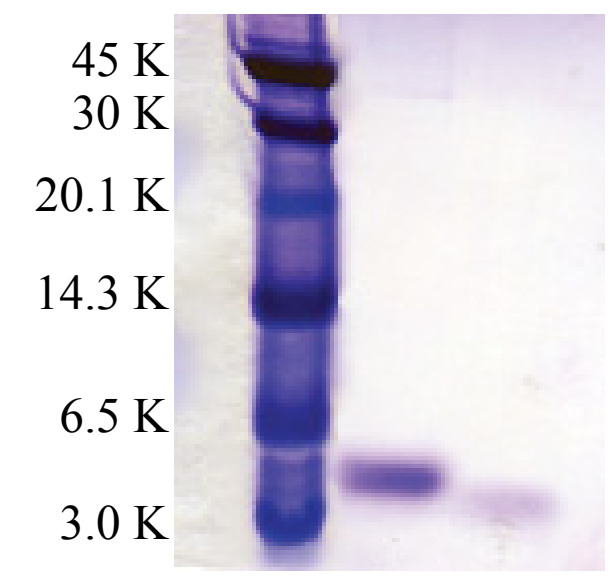

B

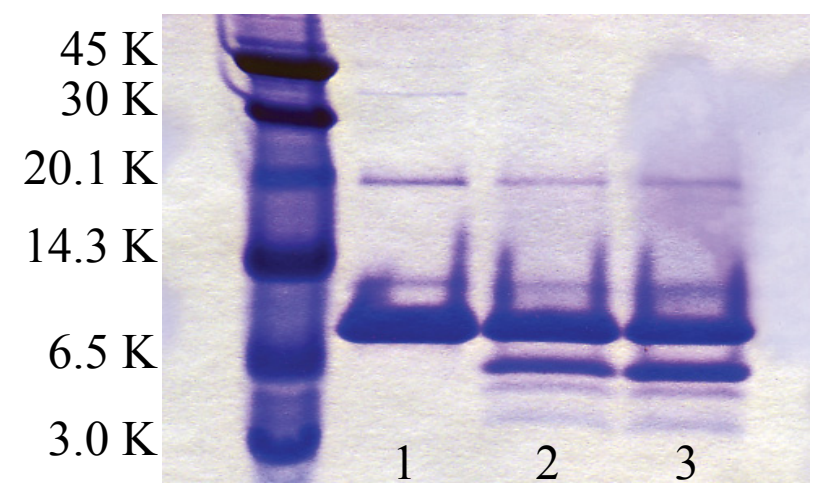

Figure 4-5. Cleavage of Peptides by Factor Xa. (A) Visualization of the efficiency of FXa cleavage on the HRA peptide (lane 2) in comparison to an uncleaved control (lane 1). (B) The efficiency of FXa cleavage on the HRBGC peptide (lane 2). Lane 3 represents HRBGC cleavage after the addition of extra FXa and a longer incubation period. Both cleaved samples are compared to an uncleaved HRBGC control (lane 1). 
Samples were loaded into a Centrifugal Filter Device (Millipore) and concentrated on an Eppendorf microcentrifuge. Resulting solutions showed large amounts of precipitate after centrifugation. Despite the success in solubilizing the HRBGC in low pH and low salt solutions, the inability to concentrate it proved to be problematic and therefore necessitated alternate methods of acquiring soluble HRBGC.

MBP Construct. Based on several studies indicating maltose binding protein (MBP) as an effective promoter of solubility [28-30] the hPIV3 F wt HRBGC peptide was subcloned into a MBP background. Sequences of the resulting plasmid were confirmed by the Hartwell Center of St. Jude Children's Research Hospital. The ease and success of subcloning the insoluble HRBGC peptide into MPB, a vector suggested as an effective chaperone for protein folding [29], holds promise as a method for quick and relatively inexpensive production of mutant hPIV3 F HRB peptides which then can be used in subsequent assays to determine HRB secondary structure.

\section{Discussion}

The ease of purification and cleavage of the HRA peptide in contrast to the difficulties encountered with the solubilization of the HRBGC peptide may be explained by a couple key differences between the peptides. As reported earlier, the HRA peptide alone easily folds into a triple stranded coiled coil conformation whereas the HRB peptide is found in an unstructured random coil conformation [20,21]. This suggests the unstable and entropic nature of the HRB peptide and the necessity of the addition of additional components to ensure proper folding and prevent aggregation.

There are a series of possible explanations for the presence of precipitate in HRB samples including the possibility that the peptide does not readily fold into its native structure, associates with other peptide molecules, and forms insoluble aggregates [29] although further structural analysis would be necessary to confirm any hypotheses regarding HRB aggregation. Attempts to coax the peptide into proper folding through protonation by suspension in a solution with a low $\mathrm{pH}$ [27] were minimally successful. HRBGC peptides were able to be solubilized but only under low salt, low $\mathrm{pH}$ conditions, and only at low peptide concentrations which limits the peptides usefulness in downstream applications. Additional attempts to use urea as a solubilizing agent $[25,26]$ were also unsuccessful in providing a useful, soluble peptide. The failure of urea to promote proper folding of the peptide and therefore prevent aggregation may be due to the way urea interacts with both the peptide and the water molecules. Studies suggest that urea actually decreases the mobility of the water molecules around the peptide by trapping them between the peptide and the urea molecules and therefore allows for increased hydrogen bonding to the peptide and higher solubility [26, 31]. Despite this encouraging information there is no evidence that a decrease in urea concentration will promote proper refolding. In fact since the urea does not seem to be directly contacting the peptide the inability to dissolve the HRBGC peptide may suggest that the removal of urea in solution would simply increase the mobility of the water molecules surrounding 
the peptide, the breaking of hydrogen bonds, and increase the tendency of the hydrophobic residues to form insoluble aggregates.

The association of the HRBGC peptide with MBP, initially used as a method of protein purification [33], has become increasingly more popular as a method of peptide solubilization and holds promise for the solubilization of the HRBGC peptide. Among the many substrate-binding proteins that have been previously studied, MBP stands out as an effective solubilizing agent able to sterically hinder aggregation [28] and also assist folding in a similar manner as a protein chaperone [28-30, 33]. Since the HRBGC appears to incorrectly fold in the presence of chemical agents, association with MBP made lead to a successful solubilization of the peptide in conditions suitable for downstream applications. Further investigation is needed in order to determine the attachment of MBP as a potential solution for peptide solubility. FXa cleavage will also be an important determinate in whether the peptide can be cleaved from MBP and still remain soluble. Cleavage and resulting soluble peptides will confirm the ability of MBP to act as chaperone and promote proper folding of the HRBGC peptide.

The work surrounding both the HRA and HRBGC peptides is still underway and will require the more efficient purification of both peptides by HPLC as well as confirmation by mass spectroscopy. The effective solubilization and purification of heptad repeat regions of the hPIV3 will allow the assessment of peptide structure and stability via a variety of analyses. First, the creation of mutations in the HRB region will provide useful information about the ability of the mutant HRB peptide to form a six helix bundle when incubated with HRA and visualizes on an SDS-PAGE gel. Circular dichroism (CD) can be used to analyze both peptide secondary structure as well as peptide stability through thermal melts. Additional studies could also include analytical ultracentrifugation which would determine composition of peptide structure by identifying expected trimeric complexes. 


\section{Chapter 5. Discussion}

The dramatic conformational changes that occur in the heptad repeat $B(H R B)$ region of the paramyxovirus $F$ protein models $[5,10]$ and the current representative models $[6$, 11] raise a variety of questions about the secondary structure of the paramyxovirus $F$ protein. Studies focusing on the HRB region will lead to a greater understanding of how the process of fusion between viral and cell membranes is initiated [10] as well as defining the role of the HRB region in F protein conformational changes and the formation of the final fusogenic hairpin structure. To date, the study of the paramyxovirus $\mathrm{F}$ protein has been largely based on the original crystal structure of the uncleaved, pre-fusion PIV5 F protein obtained by Yin et. al. in 2006 [6]. Assumptions that the HRB region is found in a triple stranded coiled coil conformation has shaped our understanding of the $\mathrm{F}$ protein and has the potential to influence the way drug therapeutics and vaccines against paramyxoviruses are designed. The research conducted in our lab on the effect of mutations in the pre-fusion F protein of hPIV3 shows potential in verifying the triple stranded coiled coil nature of the HRB region. Although still underway, assays conducted in both the pre-fusion $\mathrm{F}$ protein as well in peptides representing the HRB region will be able to verify the structure of this region.

When considering the role of the HRB region in viral and cell membrane fusion, the current model raises questions regarding the interaction of the HRB region with the $\mathrm{HN}$ protein in the initiation of fusion as well as the initiation of viral fusion beginning at the breaking apart of the three helix bundle. The HRB region of the paramyxovirus F protein is a region of considerable importance since it has the effect to further explain how the $\mathrm{F}$ protein surpasses the energy barrier necessary for the breaking of a triple stranded coiled coil conformation.

In discussing the importance of understanding the HRB region, the results obtained from the pre-fusion conformation of the hPIV3 $\mathrm{F}$ protein will be greatly enhanced by further study of peptides created from the sequence of this region. Results from the solubilization and purification of both the HRA and HRBGC peptides highlight the unique issues surrounding peptide-based experimentation as well as the success rate for peptide-based candidates for drug therapy [34]. There is reason to assume that the prefusion $\mathrm{F}$ protein will be used as a drug target by labs designing peptides to bind to prefusion intermediates and therefore prevent fusion and viral replication $[35,36]$. Several labs are already in the process of creating effective drug therapies based on the concept of peptide inhibition of fusion intermediates. These include experiments designed to test the potency of peptides derived from differing paramyxoviruses [37] as well as the effectiveness of peptides varying in length [38]. To date, it appears that the peptides, especially the HRB derived peptides, are the most effective inhibitors of viral fusion [37, 38 ] and therefore warrant further investigation as effective inhibitors of viral replication.

In closing, future work based in the area of the HRB region of the paramyxovirus $F$ protein holds potential in developing our understanding of viral fusion and in the development of effective therapeutics aimed at decreasing viral spread. With the success 
of the hPIV3 HRB derived peptides as potent inhibitors of the final fusogenic form of the F protein, knowledge of this region will increase understanding of how to create more effective peptide inhibitors that can be carried into clinical trial in the near future. 


\section{List of References}

1. Henrickson, K.J., Parainfluenza Viruses. Clin Microbiol, 2003. 16(2): p. 243-247.

2. Knipe, D.M., and P.M. Howley, Fields Virology: Fifth Edition. Lippencott Williams \& Wilkins, 2007. p. 1449-1464.

3. Horikami, S.M., et. al., Complexes of Sendai Virus NP-P and P-L Proteins Are Required for Defective Interfereing Particle Genome Replication in Vitro. J Virol, 1992. 66(8): p. 4901-4908.

4. Lee, J.K., et. al., Functional Interaction Between Paramyxovirus Fusion and Attachment Proteins. J Biol Chem, 2008. 283(24): p. 16561-16571.

5. Russell, C.J., T.S. Jardetzky, and R.A. Lamb, Membrane Fusion Machines of Paramyxoviruses: Capture of the Intermediates of Fusion. The Embo J, 2001. 20(15): p. 4024-4032.

6. Yin, H., et. al., Structure of the Parainfluenza Virus 5 F Protein in its Metastable, Prefusion Conformation. Nature, 2006. 439(5): p. 38-42.

7. Russell, C.J., et. al., A Dual-Functional Paramyxovirus F Protein Regulatory Switch Segment: Activation and Membrane Fusion. J Cell Biol, 2003. 163(2): p. 363-372.

8. Paterson, R.G., et. al, Fusion Protein of the Paramyxovirus SV5: Destabilizing and Stabilizing Mutants of Fusion Activation. Virology, 2000. 270: p. 17-30.

9. Ito, M., et. al., An Amino Acid in the Heptad Repeat 1 Domain Is Important for the Haemagglutinin-Neuraminidase-Independent Fusing Activity of Simian Virus 5 Fusion Protein. J Gen Virol, 2000. 81: p. 719-727.

10. Gravel, K.A. and T.G. Morrison, Interacting Domains of the HN and F Proteins of Newcastle Disease Virus. J Virol, 2003. 70(20): p. 11042-11049.

11. Yin, H., et. al., Structure of the Uncleaved Ectodomain of the Paramyxovirus (hPIV3) Fusion Protein. Proc Natl Acad Sci U.S.A., 2005. 102(26): p. 9290-9292.

12. Buchholz, U.J., S. Finke, and K. Conzelmann, Generation of Bovine Respiratory Syncytial Virus (BRSV) from cDNA: BRSV NS2 Is Not Essential for Virus Replication in Tissue Culture, and the Human RSV Leader Region Acts as a Functional BRSV Genome Promoter. J Virol, 1999. 73(1): p. 251-258.

13. Horvath, C.M., et. al., Biological Activity of Paramyxovirus Fusion Proteins: Factors Influencing Formation of Syncytia. J Virol, 1992. 66(7): p. 4564-4569. 
14. Russell, C.J., T.S. Jardetzky, and R.A. Lamb, Conserved Glycine Residues in the Fusion Peptide of the Paramyxovirus Fusion Protein Regulate Activation of the Native State. J Virol, 2004. 78(24): p. 13730-13739.

15. Luque, L.E., and C.J. Russell, Spring-Loaded Heptad Repeat Residues Regulate the Expression and Activation of Paramyxovirus Fusion Protein. J Virol, 2007. 81(7): p. 3132-3133.

16. Chen, L., et. al., The Structure of the Fusion Glycoprotein of Newcastle Disease Virus Suggests a Novel Paradigm for the Molecular Mechanism of Membrane Fusion. Structure, 2001. 9: p. 255-266.

17. Baker, K.A., et. al., Structural Basis for Paramyxovirus-Mediated Membrane Fusion. Mol Cell, 1999. 3: p. 309-319.

18. Zhao, X., et. al., Structural Characterization of the Human Respiratory Syncytial Virus Fusion Protein Core. Proc Natl Acad Sci U.S.A., 2000. 97: p. 14172-14177.

19. Russell, C.J., and L.E. Luque, The Structural Basis of Paramyxovirus Invasion. Trends Microbiol, 2006. 14(6): p. 243-246.

20. Joshi, S.B., R.E. Dutch, and R.A. Lamb, A Core Trimer of the Paramyxovirus Fusion Protein: Parallels to Influenza Virus Hemagglutinin and HIV-1 gp41. Virol, 1998. 248: p. 20-34.

21. Lamb, R.A., S.B. Joshi, and R.E. Dutch, The Paramyxovirus Fusion Protein Forms an Extremely Stable Core Trimer: Structural Parallels to Influenza Virus Haemagglutinin and HIV-1 gp41. Mol Mem Biol, 1999. 16: p. 11-19.

22. Dutch, R.E., G.P. Leser, and R.A. Lamb, Paramyxovirus Fusion Protein: Characterization of the Core Trimer, a Rod-Shaped Complex with Helices in Anti-Parallel Orientation. Virol, 1998. 254: p. 147-159.

23. Harbury, P.B., et. al., A Switch Between Two-, Three-, and Four-Stranded Coiled Coils in GCN4 Leucine Zipper Mutants. Science, 1993. 262: p. 1401-1407.

24. Harbury, P.B., P.S. Kim, and T. Alber, Crystal Structure of an Isoleucine-Zipper Trimer. Nature, 1994. 371: p. 80-83.

25. Wallqvist, A. and D.G. Covell, Hydrophobic Interactions in Aqueous Urea Solutions With Implications for the Mechanism of Protein Denaturation. J Am Chem Soc, 1998. 120: p. 427-428.

26. Caballero-Herrera, A., et. al., Effect of Urea on Peptide Conformation in Water: Molecular Dynamics and Experimental Characterization. Biophys J, 2005. 89: p. 852-855. 
27. Malavolta, L., et. al., Interpretation of the Dissolution of Insoluble Peptide Sequences Based on the Acid-Base Properties of the Solvent. Protein Sci, 2006. 15: p. 14761488.

28. Richarme, G., and T.D. Caldas, Chaperone Properties of the Bacterial Periplasmic Substrate-Binding Proteins. J Biol Chem, 1997. 272(25): p. 15607-15612.

29. Kapust, R.B., and D.S. Waugh, Escherichia Coli Maltose-Binding Protein Is Uncommonly Effective at Promoting the Solubility of Polypeptides to Which it Is Fused. Protein Sci, 1999. 8: p. 1669-1671.

30. Fox, J.D., et. al., Maltodextrin-Binding Proteins From Diverse Bacteria and Archaea Are Potent Solubility Enhancers. Febs Lett, 2003. 537: p. 53-54.

31. Modig, K., et. al., Water and Urea Interactions with the Native and Unfolded Forms of a $\beta$-Barrel Protein. Protein Sci, 2003. 12: p. 2770-2776.

32. Pryor, K.D., and B. Leiting, High-Level Expression of Soluble Protein in Escherichia coli Using a His ${ }_{6}$-Tag and Maltose-Binding-Protein Double-Affinity Fusion System. Protein Expression Purif, 1997. 10: p. 309-311.

33. Niiranen, L., et. al., Comparative Expression Study to Increase the Solubility of Cold Adapted Vibrio Proteins in Escherichia coli. Protein Expression Purif, 2006. 52: p. 210-213.

34. Caldwell, G.W., et. al., The New Pre-Preclinical Paradigm: Compound Optimization in Early and Late Phase Drug Discovery. Curr Top Med Chem, 2001. 1: p. 353-366.

35. Lambert, D.M., et. al., Peptides from Conserved Regions of Paramyxovirus Fusion (F) Proteins Are Potent Inhibitors of Viral Fusion. Proc Natl Acad Sci U.S.A., 1996. 93: p. 2186-2191.

36. Yao, Q., and R.W. Compans, Peptides Corresponding to the Heptad Repeat Sequence of Human Parainfluenza Virus Fusion Protein Are Potent Inhibitors of Virus Infection. Virology, 1996. 223: p. 103-112.

37. Porotto, M., et. al., Molecular Determinants of Antiviral Potency of Paramyxovirus Entry Inhibitors. J Virol, 2007. 81(19): p. 10567-10568.

38. Porotto, M., et. al., Inhibition of Hendra Virus Fusion. J Virol, 2006. 80(19): p. 9837-9846. 


\section{Vita}

Amanda Ruth Chapman was born in 1982 in the rugged mountains of Colorado. Originally interested in veterinary science, she changed her career path after attending a national youth leadership forum on medicine where she became fascinated with human science and medicine. Amanda obtained her bachelor of science at the University of Northern Colorado in 2004 and immediately accepted a job at the Colorado Center for Reproductive Medicine where she worked as a laboratory embryologist for 2 years. In 2006 she applied and was accepted to the University of Tennessee Health Science Center where she studied virology under Dr. Charles J. Russell at St. Jude Children's Research Hospital. 